\title{
Castilla y la libertad de las artes en el siglo XV. La aceptación de la herencia de Al-Andalus: de la realidad material a los fundamentos teóricos*
}

\author{
Juan Carlos Ruiz SouzA \\ Departamento de Historia del Arte I (Medieval) \\ Universidad Complutense de Madrid \\ jcruizsouza@ghis.ucm.es
}

\begin{abstract}
RESUMEN
El siglo XV en la Corona de Castilla produce uno de los paisajes monumentales más diversos y fascinantes de toda Europa. La planta centralizada en lo religioso y en lo palatino, el diseño de grandes fachadas monumentales, o el desarrollo de la plaza semipública, etc., no son más que unos pocos elementos que singularizaban el paisaje monumental de la Corona de Castilla desde el último tercio del siglo XIII, como fruto de la influencia, conscientemente aceptada, de Al-Andalus. Las formas andalusíes se fueron parcialmente agotando paulatinamente a lo largo del siglo XV ante los alardes técnicos y decorativos del último gótico procedente del centro y norte del Continente, llegado a Castilla desde 1430 aproximadamente. En los últimos años de la centuria todo se enriquece y desborda con los renovados aires renacentistas de Italia. Sólo así podremos entender tanta diversidad y libertad de planteamientos artísticos, mezclados y solapados, en donde espacios y tipologías netamente andalusíes se materializan en las formas del último gótico o del renacimiento. Obras maestras de la entidad de la Capilla de los Condestables de la Catedral de Burgos, de la fachada del Colegio de San Gregorio de Valladolid, o del Oratorio de Isabel la Católica en el Alcázar de Sevilla, entre muchas otras, solo pueden darse cita en aquella Castilla del siglo XV bajo las mencionadas coordenadas.
\end{abstract}

Palabras clave: Corona de Castilla en el siglo XV, arte gótico, arte andalusí, planta centralizada, qubba, arquitectura palatina, plaza, fachada monumental, cultura visual, paisaje monumental, formas y significados.

\begin{abstract}
Throughout the 15th century, the Crown of Castile offers one of the most diverse and fascinating monumental landscapes in Europe. The central plan prevailing within religious and palatine contexts, added to the design of monumental façades or the development of the semipublic square, etc., are but a few elements which distinguished this monumental landscape from the last third of the 13th century, as a result of the consciously-accepted influence of Al-Andalus. The Andalusi forms gradually wore out throughout the 15th century, in front of the technical and ornamental display of the late Gothic arriving in Castille from the centre and north of the Continent from around 1430. Over the last years
\end{abstract}

* El presente trabajo forma parte del proyecto de investigación del Plan Nacional $\mathrm{I}+\mathrm{D}+\mathrm{I}$, con ref. HAR2009-08901, titulado: “La Génesis del Estado Moderno y el palacio especializado. Castilla y Granada en la Baja Edad Media". 
of the century there is a general enrichment and overflow with the renewed Renaissance airs coming from Italy. Only thus can we understand such diversity and freedom in the artistic layouts developed in Castille, mixed and overlapped, where pure Andalusi spaces and typologies come to life in the forms of the late Gothic or the Renaissance. Great masterworks such as the Capilla del Condestable in Burgos Cathedral, the façade of San Gregorio College in Valladolid, or the Queen Isabel's Oratory in the Alcázar of Seville, among many others, could only emerge in Castile during the 15th century and under the circumstances above mentioned.

Keywords: Crown of Castile in the $\mathrm{XV}^{\text {th }}$ century, gothic art, andalusi art, central plan, qubba, patatine architecture, square, monumental façade, visual culture, monumental landscape, forms and meanings.

La Virgen con el Niño del Museo Municipal de Madrid atribuida a Pedro Berruguete (fig. 1), dentro de un conjunto de obras de desigual calidad asignadas a este maestro palentino, pudo ser ejecutada en los últimos años del siglo $\mathrm{XV}$. Se ha pensado que pudiera proceder del madrileño Hospital de la Latina o de la Concepción, fundado por Beatriz Galindo, dama de gran cultura perteneciente al entorno más próximo de la reina Isabel. A pesar de su desconcertante aparición a mediados del siglo XX en unos almacenes del Ayuntamiento de Madrid, evidencia las sutiles singularidades del arte del último tercio del siglo XV. En esta obra se dan cita todos los vocabularios, o mejor dicho lenguajes, artísticos del momento. El sitial de la Virgen es gótico y presenta la Anunciación en su parte superior mediante dos nichos en los que aparecen San Gabriel y la Virgen, así como un jarrón con lirios en la parte central, en alusión a su pureza. A ambos lados del trono se desarrollan dos arcos en

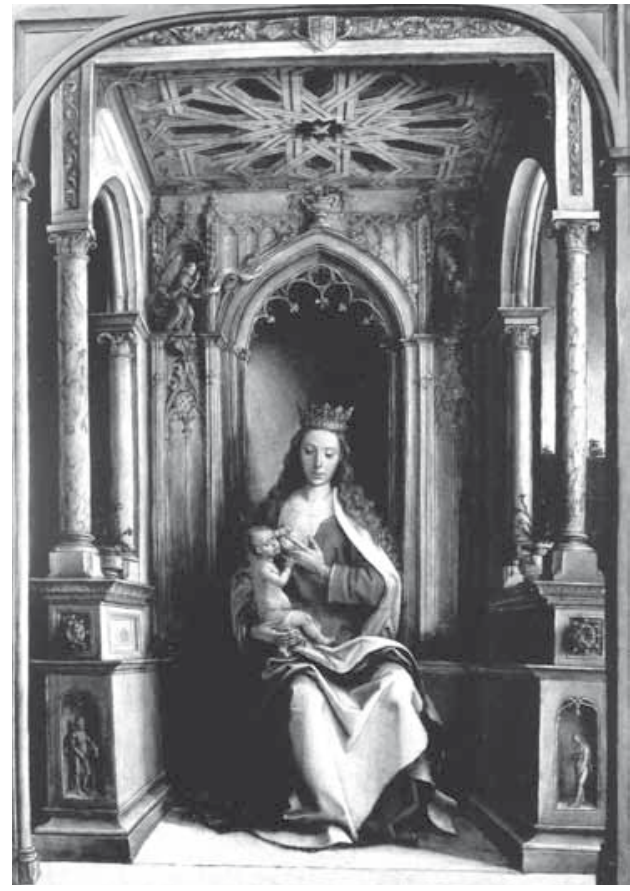

Fig. 1. Pedro Berruguete, Virgen con el Niño, ca.1500 (Museo Municipal de Madrid). los que se perciben ya las formas del renacimiento italiano, en sus columnas provistas con capiteles corintios o en la propia moldura del antepecho sobre el que se alzan, y en cuyo frente dos nichos con la representación de Adán y Eva hacen alusión a la expulsión del Paraíso. Encontramos el arte tradicional castellano en la cubierta del espacio, donde el artista de Paredes de Nava pinta una magnífica armadura de madera en cuyo centro se muestra una estrella de lazo de doce puntas, perfectamente desarrollada con todas sus partes (almendrillas, zafates y candilejos), y en cuyo centro, 
o sino, una paloma representa al Espíritu Santo, completando así la iconografía de la Anunciación antes aludida ${ }^{1}$. ¿Hasta qué punto el cuadro es una ilusión? Por la variedad de los vocabularios formales presentes en esta obra, podríamos recordar el Oratorio de la Reina Isabel en el Alcázar de Sevilla (fig. 2), donde

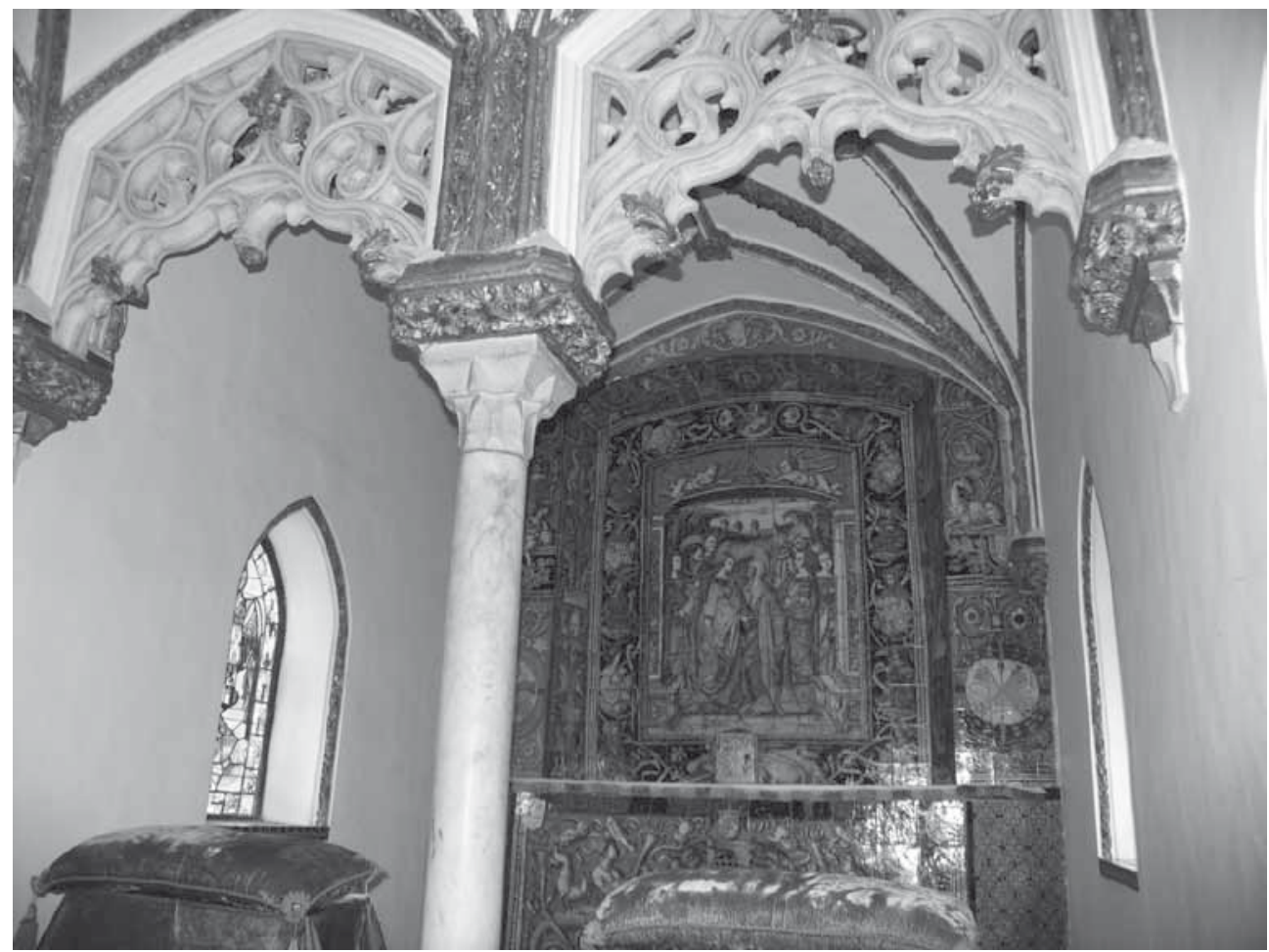

Fig. 2. Oratorio de Isabel la Católica, 1504, Alcázar de Sevilla.

un vano geminado y decorado con tracería gótica que apoya sobre un capitel de mocárabes de recuerdo nazarí, da paso al oratorio presidido por el retablo renacentista de Niculoso Pisano, realizado en cerámica y firmado por él en el año de 1504. Es muy interesante la representación de la armadura de madera en el cuadro de Berruguete, tan similar a las coetáneas todavía conservadas en las tierras palentinas de origen del artista, y así por ejemplo, en la Iglesia de Fuentes de Nava, podemos observar cómo en la armadura que precede al presbiterio se presenta en su centro, en este caso una estrella de dieciséis puntas, la imagen del Salvador. El conocimiento del paisaje monumental del momento, con sus

1 Véase la interesante y transversal lectura que del cuadro y su contexto cultural y visual realiza C. ROBINSON, "Towers, birds and divine Light: the contested territory of Nasrid and 'Mudéjar' ornament", Medieval Encounters, 17 (2011), pp. 27-79. 
lenguajes y sus significados intrínsecos, es esencial para entender la obra de Berruguete en su verdadero contexto.

\section{El siglo XV en Castilla ante la necesidad de superar los estímulos historiográficos ya establecidos}

En 1484 llegaba a España el noble de Silesia Nicolás de Popielovo en peregrinación a Compostela donde visitó el sepulcro del apóstol Santiago. Antes de abandonar el país atravesó toda la Península y fue recibido en Sevilla en audiencia por los Reyes Católicos. Le llamó la atención el protagonismo destacado que ostentaba la reina Isabel en el gobierno de Castilla junto a su marido Fernando, impresión que dejó por escrito en el relato de su viaje, donde comenta: "Es preciso hacer constar aquí un contrasentido de aquel reino en que la reina es rey, y el rey es su servidor"2.

Escritos como el de Popielovo junto a muchos otros redactados por personajes del entorno de la propia reina sirvieron para forjar la imagen legendaria que todavía hoy tenemos de Isabel la Católica, y que en gran medida monopolizan y aíslan la tópica visión de buena parte del siglo XV castellano. Es cierto que fueron muchos los acontecimientos políticos, militares, religiosos y culturales de primer orden que se sucedieron a lo largo de la centuria, especialmente durante los años de reinado de los Reyes Católicos (1474-1504), y que todavía hoy resuenan en la memoria colectiva. Las Coplas a la muerte de su padre de Jorge Manrique, el descubrimiento de América por Cristóbal Colón, la expulsión de los judíos, la conquista del reino de Granada, el Tratado de Tordesillas, la conquista definitiva de las Islas Canarias, la Gramática de Nebrija, la Inquisición y la persecución de los conversos, $\mathrm{LaCe}$ lestina de Fernando de Rojas, la introducción y difusión de la imprenta, la unión definitiva de Castilla y Aragón, el protagonismo de la artillería en la guerra..., y tantos otros nombres de personajes, hechos u obras literarias, protagonizan, acaecen o ven la luz durante el último tercio del siglo XV y primeros años del siguiente. La imagen de España descrita por el barón de Rosmithal en su viaje a la corte de Enrique IV en 1466 respecto a la que nos transmiten los viajeros que llegan a finales de la centuria o a principios del siglo $\mathrm{XVI}^{3}$, nada tienen que ver entre sí, pues aquel país sumido en la inestabilidad, en las guerras civiles endémicas y en la debilidad de la institución monárquica cambia por completo tan solo tres décadas después. En 1504 cuando la reina Isabel muere en Medina del Campo, la Corona de Castilla lideraba la política internacional europea junto a una monarquía fuerte que controlaba todas las riendas del poder.

Las manifestaciones artísticas se convierten en documentos objetivos de inestimable valor que nos permiten conocer y comprender el periodo histórico que las

\footnotetext{
J. GARCÍA MERCADAL, Viajes de extranjeros por España y Portugal, vol. I, Salamanca, 1999, p. 298.

Los relatos de todos estos viajeros se encuentran J. GARCÍA MERCADAL, op. cit., 1999, vol. I.
} 
produjeron. Durante el último tercio del siglo XV y los primeros años del siguiente el paisaje artístico y monumental de España se transformó, pero el camino se había iniciado mucho tiempo antes. La estabilidad política y la bonanza económica del último tercio del siglo XV se traduce en una verdadera fiebre constructiva, en la reforma o construcción de nueva planta de iglesias, monasterios, catedrales y palacios. Los hombres más importantes del panorama hispano, reyes, nobles y prelados, no dudaron en hacer uso de los medios artísticos para presentar sus mensajes, inquietudes, y soberbias, o simplemente para mostrar su fama y su magnificencia ${ }^{4}$.

La utilización de la heráldica con fines propagandísticos alcanzó a lo largo de la segunda mitad del siglo XV unas cotas hasta ahora inimaginables. El escudo de los Reyes Católicos presidido por el águila de San Juan, aparece con un protagonismo antes desconocido, en catedrales, puertas de entrada a ciudades, iglesias, monasterios, palacios..., y no sólo se encuentran en las obras que directamente promovieron los monarcas, ya que muchos hombres con ellos vinculados, también hicieron uso de la misma heráldica, mostrando así su participación y aceptación del proyecto político de los monarcas. Escudos de gran tamaño repartidos por toda la geografía bajomedieval de la Corona de Castilla, como los que aparecen en la fachada de la iglesia de Santiago de Orihuela, en la puerta de acceso a Toledo sobre el Puente de Alcántara (fig. 3), en el hastial de la Iglesia de Santa Clara de Bidaurreta en Oñate, en la fachada tapiz de San Gregorio de Valladolid, en el interior de San Juan de los Reyes, o en el trascoro de la Catedral de Palencia, no pueden interpretarse simplemente como un referente cronológico alusivo al gobierno de los Reyes Católicos, son la señal de todo un proyecto político, que significa la culminación de ese proceso de la "Génesis del Estado Moderno", en el que los reyes consiguen controlar y organizar sus territorios bajo su cetro.

La riqueza artística del período ha llevado a los historiadores al intento de crear un término estilístico que pudiera explicar de alguna forma lo que estaba sucediendo en la segunda mitad del siglo XV. Se ha hablado del "estilo isabelino", del "estilo Reyes Católicos", del "estilo hispanoflamenco”, del "tardogótico”..., pero realmente sin éxito ${ }^{5}$, salvo que se deje claro que su utilización se restringe estrictamente a un marco cronológico y geográfico determinado. El problema se debe a la imposibilidad de encorsetar una realidad artística tan diversa bajo el apelativo de un único término, a pesar de que la "teoría de los estilos" no desista en su empeño. Son demasiadas las diferencias que contemplamos entre obras emblemáticas del

4 Cómo no recordar aquí el magnífico catálogo de la exposición Reyes y Mecenas que tuvo lugar en el Museo de Santa Cruz de Toledo durante la primavera de 1992 comisariada por Fernando Checa y Rosario Díez del Corral. Para este punto en especial R. DÍEZ DEL CORRAL, "Arquitectura y magnificencia en la España de los Reyes Católicos", Reyes y Mecenas. Los Reyes Católicos - Maximiliano I y los inicios de la Casa de Austria en España, Toledo, 1992, pp. 55-78.

5 Véase al respecto: J.V.L. BRANS, Isabel la Católica y el arte hispano-flamenco, Madrid, 1952; y la introducción de L. TORRES BALBÁS, "Arquitectura gótica”, Ars Hispaniae, vol. VII, Madrid, 1952, pp. 323-329. 


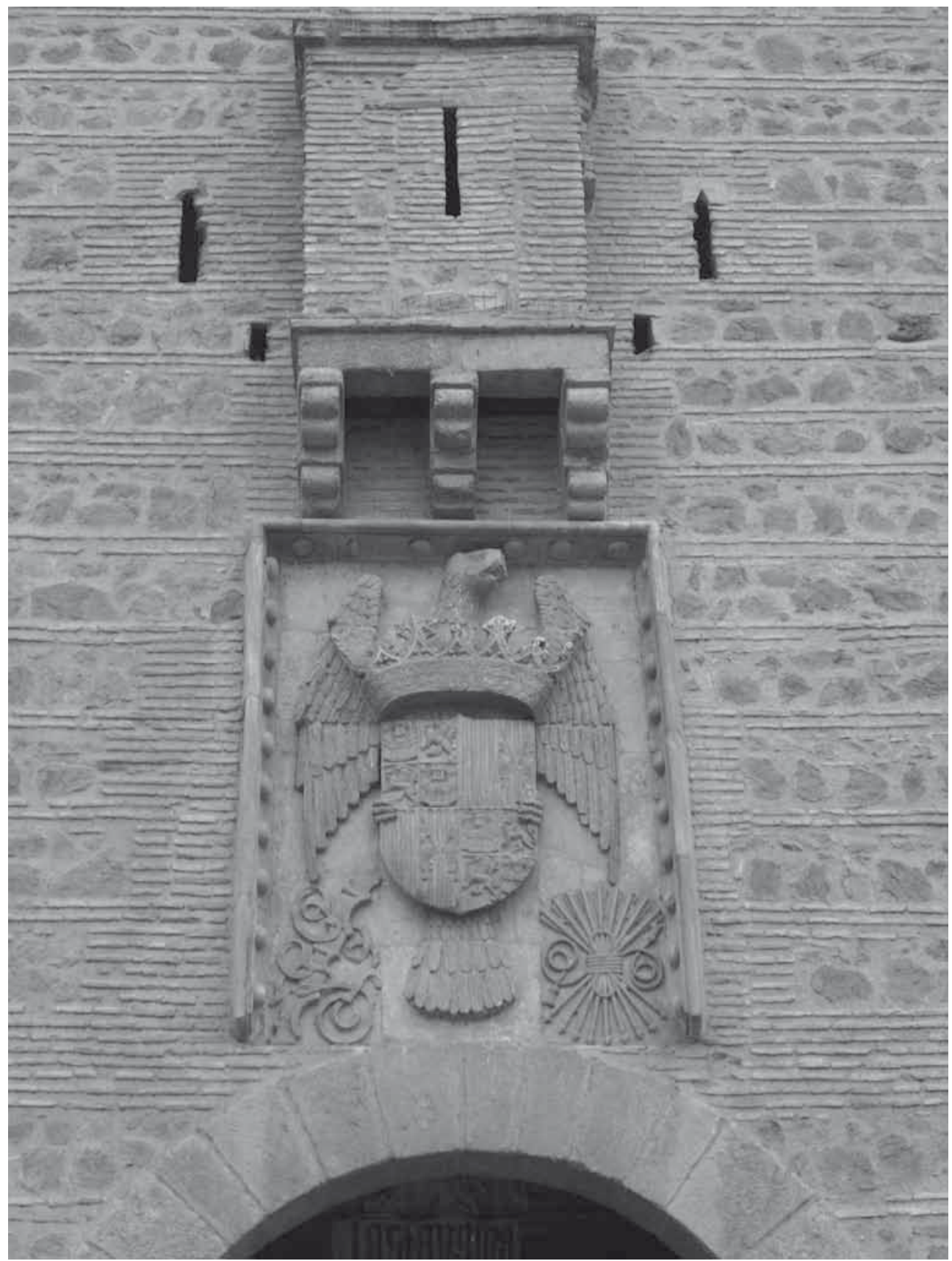

Fig. 3. Puente de Alcántara, escudo (Toledo). 
período, caso de la austera iglesia del Convento de Santo Tomás de Ávila que poco tiene que ver con el lujo ornamental desplegado en la de San Juan de los Reyes de Toledo, y eso que ambos edificios se vinculan directamente con los propios Reyes Católicos. Lo mismo podríamos decir respecto a las otras artes. Resulta asombrosa la libertad y diversidad de planteamientos ${ }^{6}$.

En multitud de ocasiones los historiadores hemos centrado nuestros esfuerzos en mostrar la superior influencia del mundo flamenco frente a la llegada de los elementos formales del renacimiento italiano, o en presentar la llegada de estos últimos al panorama bajomedieval hispano, en lugar de resaltar la riqueza y variedad de posibilidades artísticas, a la vez, en los reinos castellanoleoneses de la segunda mitad del siglo XV. Ha sido muy desafortunado el empeño que durante muchos años la historiografía ha mostrado por diseccionar el período, frustrando la imagen de diversidad, irrepetible en el panorama europeo, que presentaban los reinos de la Corona de Castilla. Si las formas artísticas pertenecían al gótico se estudiaban en ese capítulo, si por el contrario mostraban elementos procedentes del denominado renacimiento italiano, se analizaban en otro apartado. Peor suerte, si cabe, ha tenido la investigación de todas aquellas realizaciones artísticas de carácter tradicional, ya que desde mediados del "nacionalista" siglo XIX se incluyen en esa entelequia de "lo mudéjar", sencillamente por aparecer materiales de uso inmemorial en la Península (ladrillo, adobe, yeso, mampostería...) que incomprensiblemente se han vinculado exclusivamente con el mundo islámico, o por aparecer algún elemento decorativo de filiación andalusí 7 .

¿Qué sucede entonces con una obra como la Capilla del Condestable de la Catedral de Burgos (fig. 4), en la que se materializa un espacio de tradición islámica (qubba) con la técnica constructiva del gótico final? ¿Cómo debemos abordar el análisis del aludido oratorio de Isabel la Católica en la planta alta del Alcázar de Sevilla en el que tracerías góticas descansan en capiteles de mocárabes de recuerdo granadino, junto al retablo cerámico de Niculoso Pisano realizado en el lenguaje formal del renacimiento italiano? ¿Y las obras de Pedro Berruguete en las que aparecen arquitecturas con elementos góticos y renacentistas, junto a hermosas armaduras de madera de carácter genuinamente hispano? ¿Y el Cancionero de Pedro Marcuello en el que una miniatura muestra a los príncipes Felipe y Juana en un ambiente re-

6 Como punto de partida a este período véase J. YARZA, Los Reyes Católicos. Paisaje artístico de una monarquía, Toledo, 1993; R. DOMÍNGUEZ CASAS, Arte y etiqueta de los Reyes Católicos. Artistas, residencias, jardines y bosques, Madrid, 1993; así como la obra coordinada por S. CALVO CAPILLA y J.C. RUIZ SOUZA, 15 Rutas de una reina viajera. Itinerarios de Isabel la Católica, Madrid, 2004, en la que se recoge posiblemente el mayor recorrido visual de todas las artes vinculadas con los Reyes Católicos en todos sus reinos. Igualmente no olvidamos los catálogos de las exposiciones celebradas en 2004 en Medina del Campo, Hospital Real de Granada y Catedral de Toledo con motivo del V Centenario de la muerte de Isabel la Católica.

7 J.C. RUIZ SOUZA, “Le 'style mudéjar' en architecture cent cinquante ans après”, Perspective, 2 (2009a), pp. 277-286. 


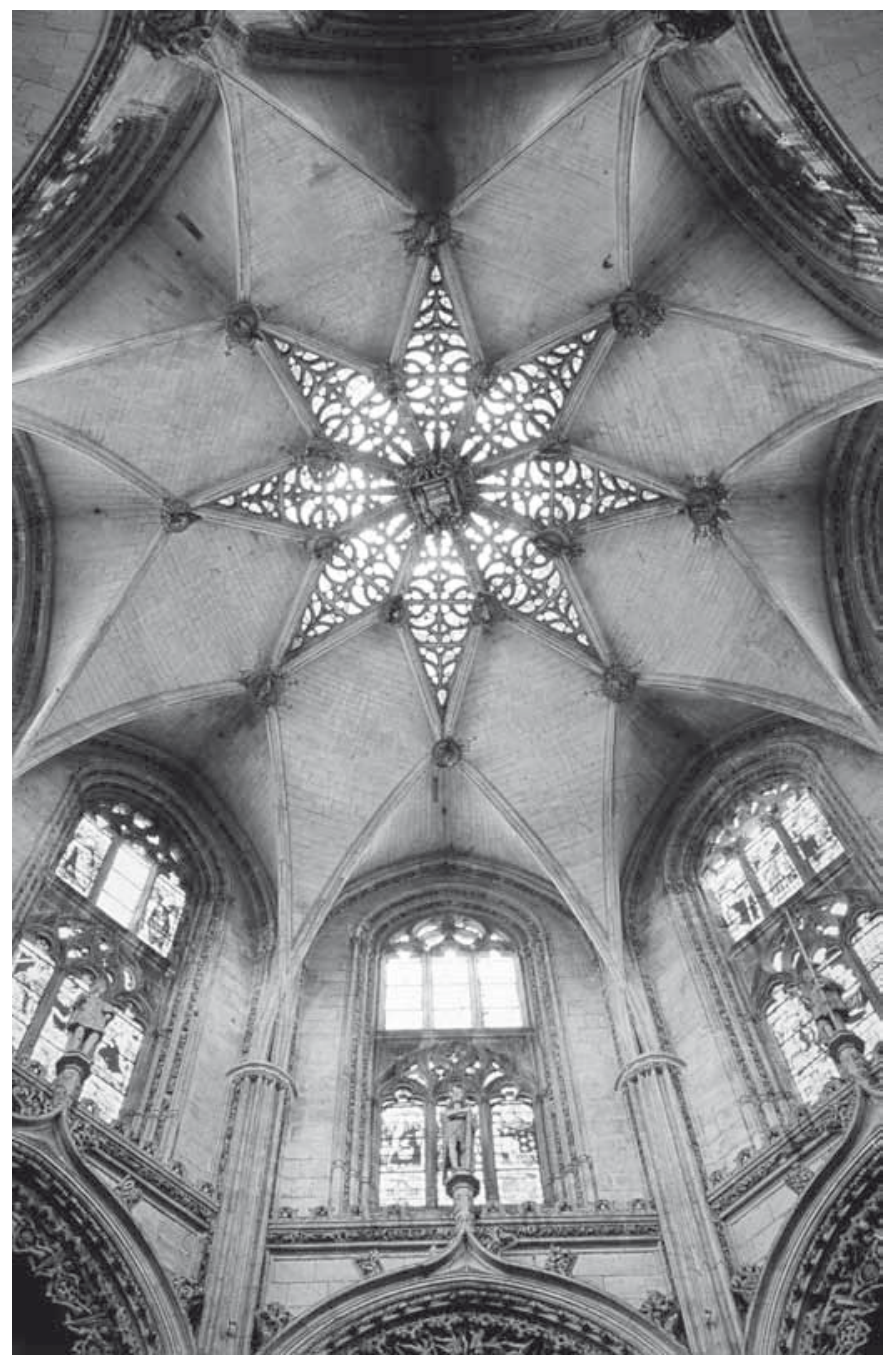

Fig. 4. Capilla de los Velasco, Catedral de Burgos, 1494. nacentista, mientras que en otra aparecen en un salón netamente gótico? ¿Y la fachada de San Gregorio de Valladolid en la que se recupera la idea de la "portada tapiz" de la madrasa islámica, igualmente con función de escuela, pero decorada con el vocabulario formal del gótico final? ${ }^{8}$ ¿Cómo debemos aproximarnos a la política artística de la familia Mendoza en su conjunto, en la que no faltan elementos formales del gótico y renacimiento, o las tipologías procedentes de Al-Andalus? Y junto a todo ello el panorama artístico se enriquecía con obras flamencas e italianas, directamente importadas, y con el arte nazarí de la Alhambra de Granada, celosamente cuidada por el Conde de Tendilla y los propios Reyes Católicos tras 1492. Sólo en la España del momento, y no en otro espacio o cronología, es posible contar con todas las obras anteriormente citadas.

Lo realmente sobresaliente del período es que la mentalidad de los hombres (promotores y artistas) fuera capaz de aceptar a la vez tal diversidad de lenguajes

8 Aspectos abordados en J.C. RUIZ SOUZA, "Castilla y Al-Andalus. Arquitecturas aljamiadas y otros grados de asimilación", Anuario del Departamento de Historia y Teoría del Arte, XVI (2004a), pp. 17-43; y en especial a lo que se refiere a la Baja Edad Media, J.C. RUIZ SOUZA, "Espacios, funciones y lenguajes arquitectónicos. La Corona de Castilla y Al-Andalus al final de la Edad Media", Pratiques du remploi au Moyen Âge dans les pays de la Méditerranée occidentale (Xe - XIII'e siècles), P. MORET (ed.), Madrid, 2009b, pp. 231-257. 
artísticos y espacios funcionales de las más variadas procedencias, que conjugaron de forma única y creativa, técnicas, materiales, formas y espacios de muy dispares procedencias. El mundo tradicional hispano -crisol de la arquitectura de los siglos precedentes- el último gótico del norte de Europa, el renacentista de Italia, o el andalusí de Granada (formas y espacios), se asimilan, reinterpretan y conjugan por los artistas del momento. Se hace necesario cambiar las coordenadas de estudio.

Comenzábamos esta breve introducción con el relato del polaco Nicolás de Popielovo, recordemos ahora al doctor Jerónimo Münzer'. Este humanista de origen austriaco, nació en Vozelberg (Tirol), consiguió el grado de doctor en medicina por la universidad de Pavía, viajó por Alemania, Italia y Francia, y visitó la Península entre 1494 y 1495, en el momento de máximo apogeo de la Corona de Castilla y Aragón, una vez concluida la conquista de Granada y producido el descubrimiento de América. Dejó por escrito, en latín, sus impresiones, las cuales constituyen el libro de viajes más emblemático del reinado de los Reyes Católicos. Nos habla de tradiciones y costumbres, de personajes, de gastronomía, de política, de los reyes, de las más variadas curiosidades, de la arquitectura que visita y también de arte. Siempre realiza análisis comparativos de lo que ve en España con respecto a lo que conoce de otros lugares de Europa, y en especial de sus tierras germanas de origen. Se detiene en muchos edificios concretos, nos habla de los palacios más importantes de la nobleza, de iglesias, monasterios y catedrales. Reflexionemos sobre varios comentarios suyos, sumamente clarificadores, al definir estilísticamente construcciones que le son ajenas. Una y otra vez se detiene en edificios ricamente decorados y cubiertos con magníficas armaduras de madera rebosantes de color. Al detenerse en la catedral de Zamora, y en especial en su claustro cubierto con ricos "artesones", define este tipo de arte como de "estilo español": "...un amplio claustro con dorados artesones al estilo español"10.

Igualmente interesantes son sus comentarios sobre el arte nazarí. Al detenerse en La Alhambra, que visita en compañía de su alcaide, el Conde de Tendilla, nos dice respecto al Generalife: "Cuando estábamos allí, vimos a muchos sarracenos adornando ya y restaurando las pinturas y las demás cosas con la finura propia suya"11.

Apreciaciones similares comenta al aproximarse a Almería: "Al acercarnos a la ciudad, ¡oh qué bellísimos huertos vimos, con sus cercas, sus baños, sus torres, sus acequias construidas al estilo de los moros, que no hay nada mejor!"12.

\footnotetext{
9 JERÓNIMO MÜNZER, Viajes por España y Portugal (1494-1495), Madrid, 1991.

10 Ibidem, p. 213.

11 Ibidem, p. 99.

12 Ibidem, p. 73.
} 
Qué interesante es el relato de Münzer para evitar ciertas confusiones. John Boswell ${ }^{13}$ considera en su clásico trabajo dedicado a los mudéjares de Aragón que una plantilla de artistas mudéjares estaría a cargo del mantenimiento de la Aljafería de Zaragoza, lo cual explicaría que artistas aragoneses fueran llamados, años después, a trabajar a la Alhambra, tras $1492^{14}$. Cree que la vinculación andalusí de las formas del palacio taifa zaragozano y de las construcciones granadinas, pudo tener alguna relación con el viaje de estos operarios a la ciudad andaluza. A lo mejor fueron llamados para realizar trabajos de un lenguaje nada andalusí, porque de hecho nada podemos observar en las orillas del Darro que nos recuerde lo más mínimo al palacio aragonés, donde se realizaron trabajos en yesería, pero con estética principalmente tardogótica.

Sería muy importante reflexionar sobre cuál era su condición social, ya que a lo mejor no eran más que simples esclavos, sobre los que los reyes ejercían su autoridad sin más. En un interesante documento reproducido por Leopoldo Piles Ros ${ }^{15}$ se habla del salvoconducto que concede en abril de 1492 el Bayle $^{16}$ general de Valencia a 28 moros aragoneses, para que vayan a la Alhambra, con el cometido de realizar trabajos de reparaciones en los palacios, por mandato del rey. Es decir, no se habla de nada más, ni si se trata de buenos o malos especialistas. Lo que sí queda claro es que no cuentan con mucha libertad de movimiento como queda patente en dicha "Letra de pasa"17, además de depender directamente del monarca. Si nos centramos en los documentos, estos artesanos parece que se ocuparían tan sólo de obras de mantenimiento: “...adobar, calçar paredes, retejar y en las obras menudas y viejas..."18, al fin y al cabo tal como Jerónimo Münzer nos explica parece que seguían siendo artesanos nazaríes los que seguían realizando sus labores moriscas.

A pesar del protagonismo indiscutible que adquiere el reinado de los Reyes Católicos en el último tercio del siglo $\mathrm{XV}$, y de la espectacularidad del momento, es imprescindible que no perdamos la vista completa de la centuria, pues de lo contrario la analizaremos erróneamente, y en muchas ocasiones más desde el siglo XVI que desde sus fuentes anteriores enraizadas en gran medida en la propia Corona castellana de los siglos XIII y XIV, y de la primera mitad del siglo $\mathrm{XV}^{19}$.

13 J. BOSWELL, The Royal treasure. Muslim Communities under the Crown of Aragón in the Fourteenth Century, London-New Haven, 1977, p. 57.

14 A. DE LA TORRE Y DEL CERRO, "Moros zaragozanos en obras de la Aljafería y de la Alhambra", Anuario del cuerpo facultativo de Archiveros, Bibliotecarios y Arqueólogos, III (1935), pp. 249-255.

15 L. PILES ROS, Estudio documental sobre el Bayle General de Valencia, Valencia, 1970, doc. 7, p. 314.

16 El "Bayle" era un alto funcionario con amplias competencias, que representaba los intereses del monarca en Valencia.

17 Salvoconducto.

18 A. DE LA TORRE Y DEL CERRO, op. cit., 1935, p.254.

19 Al respecto es de gran interés utilizar como punto de partida del arte del siglo XV en España el reciente número 334, monográfico, de la revista Goya, que hemos coordinado y dedicado al arte de la primera 


\section{El paisaje monumental de la Corona de Castilla y sus opciones ${ }^{20}$. De la reinteriorización del siglo XIV a la revolución de las formas del último gótico}

El análisis de la arquitectura de un territorio tan amplio como es la Corona de Castilla y de León en el siglo XV, debe partir de una aproximación a su paisaje monumental, de la misma manera que no debe olvidarse la formación y el propio bagaje que traen consigo los artistas formados allende los Pirineos. Sólo así podremos comprender que en el segundo cuarto del siglo XV, en el Convento de Santa Clara de Tordesillas, directamente vinculado al rey Juan II, se estén construyendo a la vez el presbiterio de su iglesia $^{\mathbf{2 1}}$, cubierto con una espectacular armadura de madera con decoración de lazo (fig. 5), la más espectacular de Castilla junto a la coetánea del Salón de Embajadores del Alcázar de Sevilla, y justo a su lado la preciosa Capilla del Contador Saldaña (fig. 6), que bien podríamos encontrar en Borgoña, si atendemos a sus exquisitas formas del último gótico y que hemos vinculado con el artista Ysambart y con el

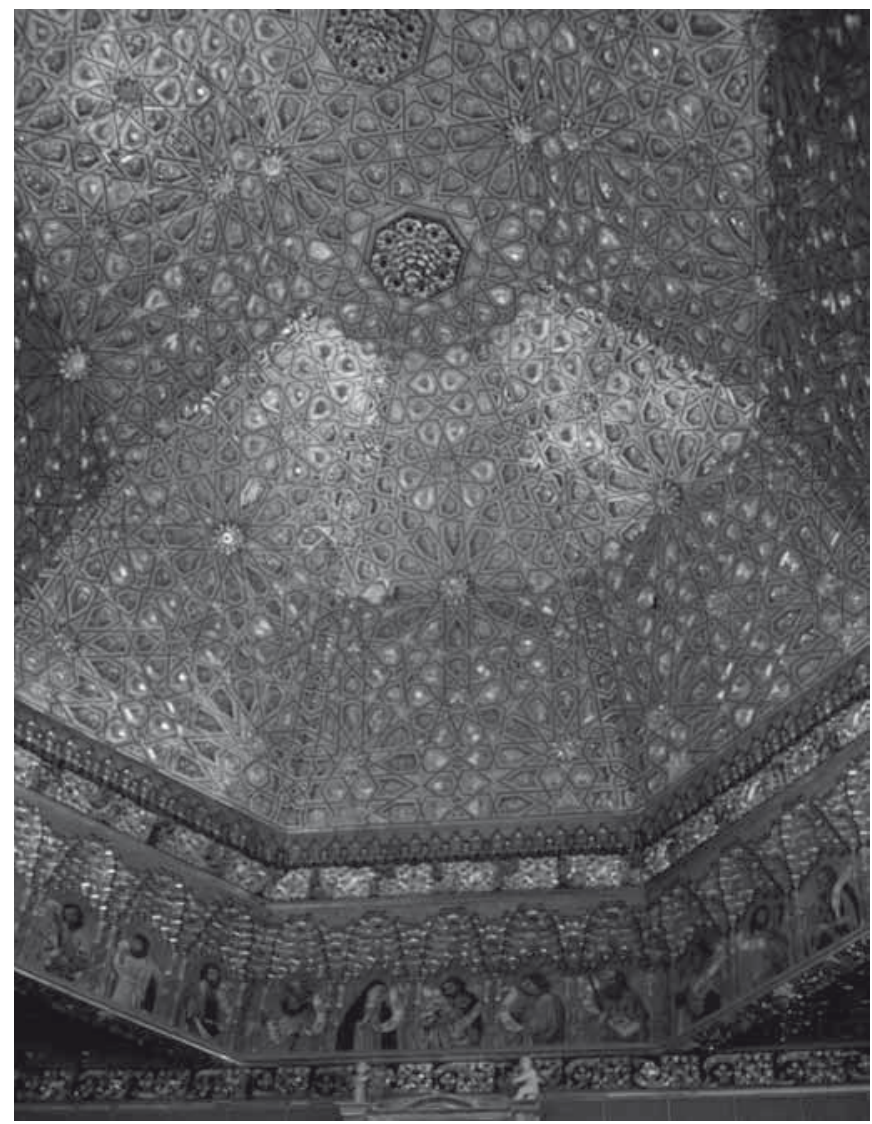

Fig. 5. Santa Clara de Tordesillas, presbiterio, segundo cuarto del siglo XV (Valladolid).

parte de la centuria en el que se incluyen los artículos de María Victoria Herráez Ortega, María del Valle Gómez de Terreros Guardiola, Javier Martínez de Aguirre, Amadeo Serra Desfilis y de Fernando Villaseñor; así como la introducción bibliográfica realizada por la profesora Matilde Miquel.

${ }^{20}$ Debemos recordar el espíritu del trabajo de X. BARRAL I ALTET (dir.), Le paisaje monumental de la France autour de l'an mil, París, 1987, fruto del coloquio internacional organizado en 1987 con motivo del milenario de la coronación del primer rey capeto.

${ }_{21}$ J.C. Ruiz Souza, "La iglesia de Santa Clara de Tordesillas. Nuevas consideraciones para su estudio", Reales Sitios, 140 (1999), pp. 2-13. 


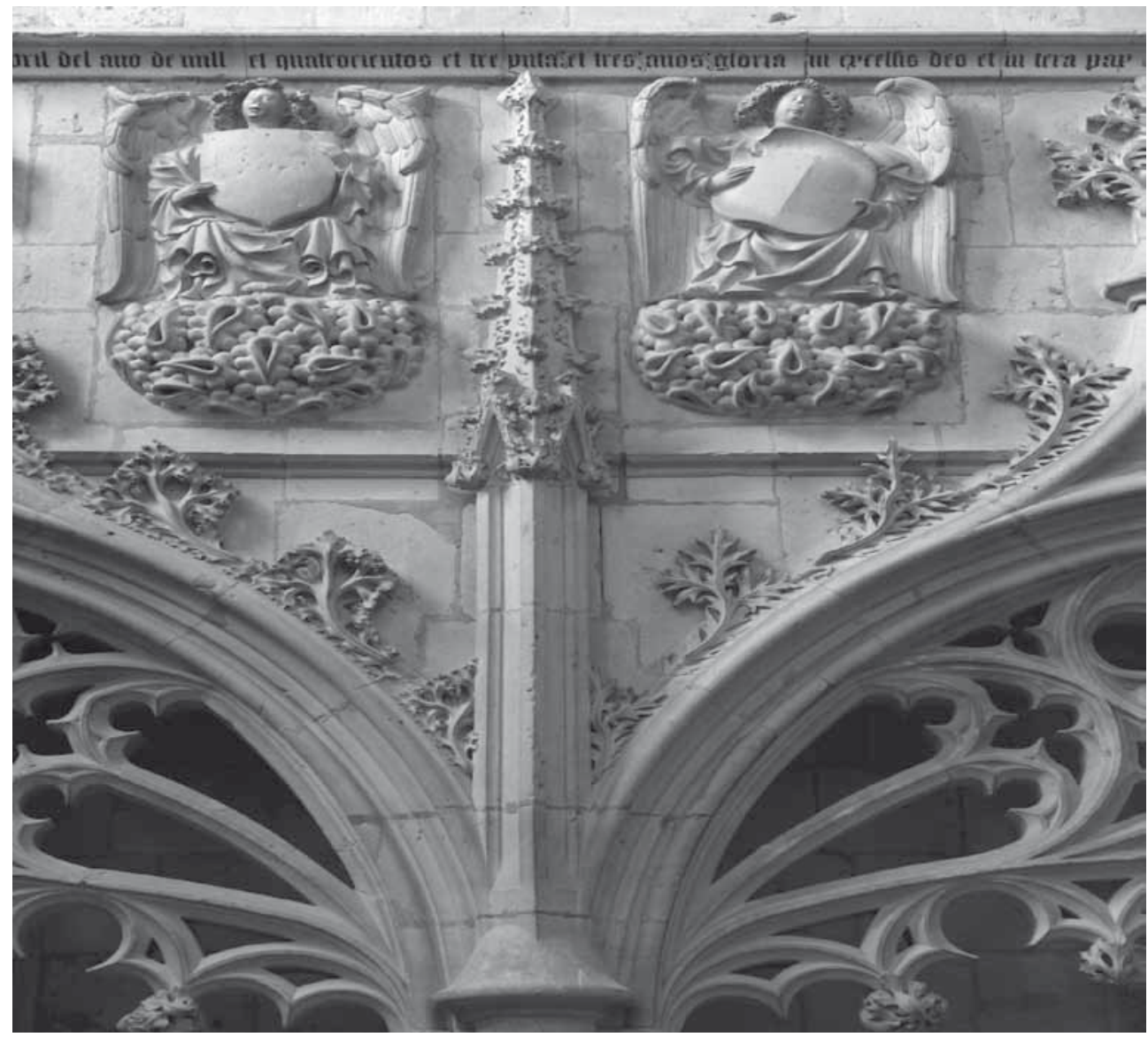

Fig. 6. Capilla del Contador Saldaña, Santa Clara de Tordesillas, segundo cuarto del siglo XV (Valladolid).

patronato de la familia Luna ${ }^{22}$. Un territorio que se dilata desde el Cantábrico al Estrecho de Gibraltar, donde se superponen tradiciones y paisajes muy diversos, vividos por unos mismos personajes que se encuentran en continuo movimiento ante la itinerancia constante de la corte. Es muy tentador ceñirse a unidades administrativas anacrónicas y actuales, y reinventar paisajes diferentes a los que realmente existieron. El estudio del periplo realizado por los promotores a través de sus territorios nos pone ya sobre aviso. Resulta todavía sorprendente observar hasta qué punto los Reyes Católicos ${ }^{23}$ recorren todos sus territorios sin excepción, y lo mismo podemos decir de la nobleza y del alto clero que recorre la Corona

22 A. GARCÍA FLORES y J.C. RUIZ SOUZA, "Ysambart y la renovación del gótico final en Castilla: Palencia, la Capilla del Contador Saldaña en Tordesillas y Sevilla. Propuesta de trabajo", Anales de Historia del Arte, 19 (2009), pp. 43-76.

23 A. RUMEU DE ARMAS, Itinerario de los Reyes Católicos, Madrid, 1974. 
en su conjunto. ¿Y los artistas? Desgraciadamente no conocemos tantos datos en Castilla como sí sucede en Aragón, pero noticias como las del artista Ysambart, que, procedente de Francia, lo encontramos en Lérida, Zaragoza, Daroca, Palencia o Sevilla ${ }^{24}$, a lo largo de la primera mitad del siglo XV, no debería hacernos dudar sobre la enorme movilidad de los grandes maestros que van organizando talleres a su paso, lo que les permite compatibilizar trabajos lejanos. Todo ello explica la necesidad de conocer el paisaje monumental de territorios tan amplios.

En otros estudios hemos abordado ya el tema de las influencias existentes y mutuas entre la arquitectura cristiana y andalusí en la España medieval ${ }^{25}$, por lo que ahora nos gustaría aprovechar este ensayo para repetir y retomar algunas reflexiones que nos inviten a replantearnos algunos de los pilares que más han influido en el arte medieval español.

En estas líneas nos gustaría abordar el tema de la influencia de la arquitectura islámica en territorio cristiano en la Baja Edad Media, en particular en el controvertido siglo XV. Influencia que sin duda existió y fue de gran intensidad. Los edificios, antes que un estilo, son espacios creados para unas determinadas funciones, en multitud de ocasiones dotados de un mensaje ideológico claro.

Hubo edificios en Al-Andalus que fueron copiados y emulados por los cristianos, entendiendo la diferencia que existe entre ambos vocablos tal como ya apuntó Krautheimer ${ }^{26}$ en su clásico estudio dedicado al Santo Sepulcro. Edificios que se convirtieron en fuentes de modelo de la cultura visual de lo sagrado y del poder. Fue de gran envergadura el impacto que tuvo a lo largo de toda la Edad Media la Mezquita de Córdoba entre los reinos cristianos que terminarían configurando la Corona de Castilla y de León, y de ella según el momento se tomaron aspectos más o menos complejos, sin duda, cargados de gran significado. En un plano puramente decorativo y simbólico, el profesor Bango escribe sobre el sentido que en el siglo IX podían tener los merlones escalonados, de recuerdo omeya-cordobés, dispuestos en la arquitectura y pintura del prerrománico asturiano, como alusión a la fortaleza de la $\mathrm{fe}^{27}$. Podríamos continuar nuestro discurso con los arcos de herradura trasdosados con alfices de la arquitectura de

24 A. GARCÍA FLORES y J.C. RUIZ SOUZA, op. cit., 2009, pp. 47-52; J. IBÁÑEZ FERNÁNDEZ y J. CRIADO MAINAR, "El maestro Isambart en Aragón: la Capilla de los Corporales de Daroca y sus intervenciones en la Catedral de la Seo de Zaragoza", A. JIMÉNEZ MARTÍN (ed.), La piedra postrera. V Centenario de la conclusión de la Catedral de Sevilla, Simposium internacional sobre la Catedral de Sevilla en el contexto del gótico final, vol. II, Sevilla, 2007, 75-114.

25 J.C. RUIZ SOUZA, "Toledo entre Europa y Al-Andalus en el siglo XIII: Revolución, tradición y asimilación de las formas artísticas en la Corona de Castilla", Journal of Medieval Iberian Studies, I/2 (2009c), pp. 233-271.

26 R. Krautheimer, "Introduction to an 'Iconography of Mediaeval architecture",, Journal of the Warburg and Courtauld institutes, V (1942), pp. 1-33.

27 I. Bango, "El verdadero significado del aspecto de los edificios. De lo simbólico a la realidad funcional. La iglesia encastillada", Anuario del Departamento de Historia y Teoría del Arte, IX-X (1997-98), pp. 53-72, especialmente pp. 59 y ss. 
los siglos X-XI, con los modillones de rollo del prerrománico, con las cúpulas de arcos entrecruzados de la macsura de la ya citada ampliación de al-Hakam II imitadas en edificios de los siglos XII y XIII (cimborrio de San Miguel de Almazán, cúpula del Santo Sepulcro de Torres del Río, templete interior de la Vera Cruz de Segovia, etc.), con las tres cúpulas de la entrada de la Capilla de la Asunción de las Huelgas de Burgos que emulan en el último tercio del siglo XIII a las tres cúpulas iniciales de la ampliación de al-Hakam II, con el ritmo de arcos de la misma ampliación califal que hallamos en la Capilla Dorada de Santa Clara de Tordesillas erigida durante la primera mitad del siglo XIV, o con las fachadas de la mezquita cordobesa reinterpretadas en tantas iglesias toledanas construidas entre los siglos XIII y XIV principalmente ${ }^{28}$.

Ante la reinteriorización que sufre la Corona de Castilla a todos los nive$\operatorname{les}^{\mathbf{2 9}}$ entre el último tercio del siglo XIII y los primeros años del XV, se produjo un ambiente propicio para asimilar todo lo que encarnaban las construcciones andalusíes (espacios, lenguajes arquitectónicos, y mensajes ideológicos), especialmente almohades y nazaríes, ya que el reino vasallo de Granada estaba viviendo la etapa más rica y creativa de su historia. En dicho ambiente observamos las cúpulas de mocárabes erigidas por próceres cristianos para monumentalizar espacios funerarios, al ser plenamente conscientes de su dimensión religiosofuneraria $^{30}$. Lo mismo se podría decir de ciertos palacios de la monarquía y de la nobleza, especialmente de las construcciones auspiciadas por el rey Pedro I de Castilla (1350-1369), bajo cuyo reinado se construyeron el palacio de Tordesillas y el Alcázar de Sevilla. Don Pedro emuló las construcciones islámicas, en particular la Alhambra, ya que en ella encontró un palacio especializado, donde existían salones del trono, salas destinadas al ejercicio de la justicia, grandes fachadas y patios concebidos para la gloria del monarca. Palacio especializado que se ajustaba a las necesidades de lo que hoy conocemos como la "Génesis del Estado Moderno", ya aludido en estas páginas, es decir, un estado especializado que se caracteriza por la concentración del poder en manos del monarca en detrimento del clero y de la nobleza. Al final los palacios de Al-Andalus se convirtieron en una opción a emular por la nobleza castellana de la Baja Edad Media tal como nos recuerda la profesora Pérez Higuera ${ }^{31}$.

28 Aspectos abordados en J.C. RUIZ SOUZA, “Al-Andalus y Cultura Visual. Santa María la Real de las Huelgas de Burgos y Santa Clara de Tordesillas: Dos hitos en la asimilación de Al-Andalus en la reinteriorización de la Corona de Castilla y León”, M. VALDÉS (ed.), El legado de Al Andalus. El arte andalusí en los reinos de León y Castilla durante la Edad Media León, Valladolid, 2007a, pp. 205-242.

29 Véase al respecto J.C. RUIZ SOUZA, Estudios y reflexiones sobre la arquitectura de la Corona de Castilla y Reino de Granada en el siglo XIV: creatividad y/o crisis, Tesis inédita en microfichas, Madrid, Universidad Autónoma de Madrid, 2000.

30 J.C. RUIZ SOUZA, "La cúpula de mocárabes y el Palacio de los Leones de la Alhambra", Anuario del Departamento de Historia y Teoría del Arte, XII (2000), pp. 9-24.

31 M.T. PÉREZ HIGUERA, "El Mudéjar, una opción en la Corte de Castilla y León", Historia del Arte de Castilla y León. Arte Mudéjar, vol. IV, Valladolid, 1994, pp.129-222. 


\section{El particularismo del siglo XV. Tradición y revolución. Conjugando espacios y lenguajes técnico-formales}

El siglo XIV es esencial para comprender la arquitectura del siglo XV en la Corona de Castilla. Durante aquella centuria se asimilaron espacios y formas andalusíes con todas sus consecuencias tal como hemos repetido en tantas ocasiones ${ }^{32}$. Dicho proceso converge después con la revolución técnico-formal procedente de Europa.

A finales del siglo XIV Europa vive uno de los momentos más esplendorosos en lo que se refiere al mundo de las artes en su conjunto. En torno a 1400, o mejor dicho entre 1385 y 1415 todas las artes van a experimentar un gran impulso de renovación en la corte de París y en los diferentes ducados franceses, como el de Berry o el de Orleans, y muy en especial en el de Borgoña tan vinculado con Flandes, ante la unión de ambos territorios tras el enlace matrimonial entre Felipe el Atrevido y Margarita de Flandes en 1369. Muchos artistas, especialmente flamencos, acudirán a trabajar a unos ducados en los que se conocían también los aires renovadores del Trecento italiano toscano gracias a la presencia de una nutrida colonia de comerciantes y banqueros italianos. El eje Borgoña-Flandes supondrá además el inicio de la superación de la elegante estética del "gótico internacional" que ahora también estaba viviendo su momento más destacado, a favor de un arte donde la monumentalidad, la vitalidad, el realismo y el sentimiento se van abriendo paso en las artes figurativas, marcando el arranque del denominado "renacimiento del norte".

En semejante ambiente la arquitectura del último gótico fue capaz de renovarse ante los valores intrínsecos que encontró en lo decorativo frente a problemas simplemente estructurales que parecen pasar a un segundo plano. La arquitectura se vuelve versátil, se camufla entre molduras, diseños geométricos, tracerías y follajes, y más bien parece convertirse en el pedestal de la escultura figurativa monumental, tal como se evidencia en la chimenea del palacio ducal de Poitiers realizada por el maestro Guy de Dammartin (1384-1390). La personalidad del arquitecto Jean de Marville, de escultores como Claus Sluter o Claus de Werve, de pintores como Jean Malouel o los hermanos Limbourg, junto a muchos otros, y, repetimos, en muchas ocasiones de origen flamenco, junto al decidido mecenazgo de los promotores de la casa Valois, es decir de Carlos VI de Francia, y sus tíos, hermanos de Carlos V, Louis d'Orleáns, Jean de Berry o Felipe el Atrevido, y sin olvidarnos de los hombres que a su servicio acaparaban los altos cargos de la administración, marcarán en gran medida la estética artística de buena parte de Europa durante la primera mitad del siglo XV. Promotores que entendieron que la inversión en empresas artísticas formaba parte de su estatus y su fama. La diáspora de muchos de sus artistas, en parte favorecida por la crisis que sufre Francia a partir de la segunda década del siglo XV ante el conflicto que mantiene con Inglaterra, facilitó la difu-

\footnotetext{
32 Vid. nota n. 9.
} 
sión de las nuevas formas por toda Europa, al forzar la emigración de centenares de artistas (orfebres, pintores, miniaturistas, maestros de la construcción, escultores...) por todo el Continente, y también por España ${ }^{33}$.

Es importante que comprendamos todo este proceso flamenco-franco-borgoñón con una mirada amplia ya que los mecenas se conocían entre sí, compartían artistas e incluso empresas, y fue común que todos ellos acudieran a París en busca de encargos y artífices, de ahí que se haya acuñado el término de "París 1400"34 en alusión a todo ese ambiente artístico tan versátil, tan escurridizo y tan internacional. Dichos promotores construían palacios en la ciudad del Sena, desde donde planificaban las empresas artísticas de sus territorios de origen. Por todo ello no debemos ser muy reduccionistas y hablar tan sólo de la influencia de Borgoña, Flandes o Alemania, por la procedencia de sus artistas, ya que fue común que un mismo personaje de origen flamenco pudiera aprender o perfeccionar el oficio en París, por ejemplo, donde toda la clientela del momento se daba cita, y luego aparecer en varios ducados diferentes, en Berry, en Borgoña, en Orleáns, en cualquier localidad de la Isla de Francia, o en cualquier empresa artística del momento, independientemente del lugar ${ }^{35}$. Desgraciadamente todavía hoy desconocemos mucho respecto a la relación que existió entre los diferentes reinos hispanos y los mencionados ducados galos, entre los que hubo intercambios de embajadas y regalos, y más tras el ascenso al trono de los Trastámara en 1369 al convertirse Castilla en aliada de la corona francesa ${ }^{36}$.

A dicho proceso se une un acontecimiento trascendental que navega en la misma dirección y que también facilita la llegada del arte europeo a Castilla, como fue la celebración del Concilio de Constanza, iniciado en 1414, con el propósito de solucionar el denominado Cisma de Occidente. Concilio al que llegan importantes prelados hispanos, quienes además de discutir sobre el futuro de la Iglesia, pudieron ver con sus propios ojos los derroteros artísticos que se estaban viviendo en el centro del continente y de paso atraer a maestros del tardogótico. En ese ambiente

33 Debido a que es inmensa la bibliografía existente al respecto recomendamos dos títulos que sirven para conocer muy bien todo este período. Nos referimos al catálogo de la exposición Les arts sous Charles VI. París 1400, París, 2004, celebrada en el Museo del Louvre durante la primavera del 2004 bajo la dirección de E. TABURET-DELAHAYE, y el catálogo de la exposición L'art à la cour de Borgogne. Le mécénat de Philippe le Hardi et de Jean sans Peur (1364-1419), París, 2004, celebrada en el Musée des Beaux-Arts de Dijon durante el verano de 2004 y comisariada por S.N. FLIEGEL y S. Jugie.

34 Ibidem.

35 Les arts sous Charles VI, 2004, especialmente pp. 74-156.

36 A modo de muestra el Duque de Berry regaló a finales del siglo XIV a la reina Catalina de Lancáster el famoso portapaz de la Virgen con el Niño que hoy se conserva en el tesoro de la Capilla de los Condestables de la catedral de Burgos, al pasar su pertenencia a la familia de los Velasco. A. FRANCO MATA, "Las artes decorativas en el territorio burgalés durante el periodo gótico", El arte gótico en el territorio burgalés, Burgos, 2006, pp. 347-349. Véase también: J. DOMENGE, "Regalos suntuarios: Jean de Berry y la realeza hispana", El intercambio artístico entre los Reinos Hispanos y las cortes europea en la Baja Edad Media, León, 2009, pp. 343-363, donde pueden consultarse otras referencias del mismo autor sobre este tema. 
se enmarca la labor de decisivos obispos, como fue la de Sancho de Rojas, recientemente estudiada por la profesora Herráez Ortega ${ }^{37}$.

Recapitulando y volviendo a Castilla, desde el reinado de Juan II, especialmente durante el segundo cuarto del siglo XV, llegan con fuerza implacable los maestros y las formas de la arquitectura del norte de Europa. Formas aún sin contaminar por el "paisaje monumental" que por entonces existía en las tierras de la Corona de Castilla. Los obispados de Burgos, Palencia y Toledo lideran el cambio arquitectónico con la construcción de obras netamente borgoñonas, flamencas o alemanas de gran calidad, así se demuestra en la citada Capilla de los Saldaña en la iglesia de Santa Clara de Tordesillas, en las numerosas intervenciones que tuvieron lugar en la catedral de Toledo, en la ciudad de Palencia o en las agujas de la fachada de la catedral de Burgos, etc. Las formas decorativas procedentes de Al-Andalus y que con tanta delicadeza exornaron los palacios de Tordesillas, Toledo, Córdoba o Sevilla, caso de las yeserías, comienzan su decadencia al realizarse con una factura más tosca y pobre (ejemplos de Sigüenza -arcos de la Casa del Doncel y del Museo Episcopal-, Guadalajara -yeserías del alcázar-, Sahagún -Iglesia de la Peregrina-, Medina del Campo -Palacio Real-, Mayorga -Iglesia de Santa María de Arbás-, etc $^{38}$.)

Durante el siglo XV asistiremos al sutil y brillante final de todo el proceso de asimilación formal de lo andalusí, iniciado en los siglos VIII y IX. Los espacios y tipologías arquitectónicas andalusíes, muchas ellas de indudable origen clásico romano, serán materializadas con las nuevas formas procedentes del último gótico europeo que permiten mayores alardes técnicos. Sólo así comprenderemos la peculiaridad del siglo XV castellano, que se sale de todos los esquemas historiográficos de estudio establecidos para otras regiones de Europa.

\section{La planta centralizada en la expresión del poder. Del salón del trono al presbiterio privatizado}

La planta centralizada constituye un capítulo esencial en el estudio del particularismo de la arquitectura del siglo XV y cuyo origen hemos ubicado en el estudio de la qubba islámica ${ }^{39}$. Se construyeron qubbas regias de carácter civil como nos

37 Nos referimos a su precioso artículo: M.V. HERRÁEZ ORTEGA, "Castilla, el Concilio de Constanza y la promoción artística de don Sancho de Rojas”, Goya, 334 (2011), pp. 5-19.

38 Véase todo este proceso en J.C. RUIZ SOUZA, "La yesería decorativa bajomedieval", F. REGUERAS GRANDE y A. SÁNCHEZ DEL BARRIO (coords.), Arte Mudéjar en la provincia de Valladolid, Valladolid, 2007b, pp. 47-59.

39 Véase al respecto el estudio monográfico sobre este asunto: J.C. RUIZ SOUZA, "La planta centralizada en la Castilla Bajomedieval: entre la tradición martirial y la qubba islámica. Un nuevo capítulo de particularismo hispano", Anuario del Departamento de Historia y Teoría del Arte, 13 (2001a), pp. 9-36. En él además presentamos una amplia bibliografía de los distintos autores que han tratado el tema, caso de Pavón Maldonado o Manzano Martos. 
recuerda Manzano Martos ${ }^{40}$. Salones centralizados que la realeza y la nobleza utilizaron en sus palacios como escenario de representación y propaganda del poder, y así estudiamos los tres ejemplos conservados en el Alcázar de Sevilla (el Salón del Trono en alto dispuesto tras la fachada de la Montería, el Salón de Embajadores y la Sala de la Justicia), el gran salón ubicado en la torre más alta del alcázar de los Velasco en Medina de Pomar (Burgos), el Corral de Don Diego de Toledo, las "qubbas regias" conservadas en ciertos palacios hispalenses (Casa Olea y Palacio de Altamira), o la gran qubba recientemente estudiada y descubierta por Julio Navarro Palazón en el Alcázar de Guadalajara ${ }^{41}$. Desde allí, es decir, desde el siglo XIV al que pertenecen los ejemplos aludidos, llegaremos al gran salón, tipo qubba, que en el siglo XVI se erigió en la Casa de Pilatos de Sevilla, sin olvidarnos de otras del siglo XV, caso del Salón del Solio del Alcázar de Sevilla o la que aún existe en Belmonte perteneciente a la familia de los Villena.

Según avanzamos en el tiempo vemos como los espacios andalusíes se comienzan a materializar en el nuevo lenguaje técnico que procede del gótico final. ¿Cómo debemos adjetivar a éstos últimos?, curiosamente nadie duda en denominarlos góticos si presentan esta técnica, y en cambio se olvidan de su propia esencia: el espacio y su función.

En la arquitectura religiosa lo más relevante es observar la incidencia que sigue teniendo la construcción de qubbas funerarias. Si en el siglo XIV se construían con las formas andalusíes, caso de la Capilla Real de Córdoba erigida por Enrique II en 1371, en la centuria siguiente vemos que todo cambia, y así, un edificio tan emblemático como la Capilla de los Condestables de Castilla en la catedral de Burgos (fig. 4) construida por Simón de Colonia a finales del siglo, es incomprensible sin tener en cuenta la tradición existente en Castilla de capillas funerarias de planta centralizada construidas durante la centuria anterior, caso de la capilla funeraria construida junto a la cabecera de San Pablo de Córdoba o las capillas funerarias del monasterio pacense de Tentudía, entre muchas otras ${ }^{42}$. Capillas que continúan la idea martirial antigua pero de la mano de la arquitectura de Al-Andalus, donde las fundaciones de carácter centralizado continuaron siendo una constante a lo largo de toda la Edad Media.

A lo largo del siglo XIV, en el ámbito religioso las qubbas y oratorios de carácter privado y generalmente funerario que se abrían en las naves de los templos, terminarán ocupando la propia cabecera de la iglesia ${ }^{43}$. No se trata de que el tramo

40 R. Manzano Martos, La Qubba, aula regia en la España Musulmana, Madrid, 1994.

41 J. NAVARRO PALAZÓN, "El Alcázar Real de Guadalajara. Un nuevo capítulo de la arquitectura bajomedieval española”, J.M. MILLÁN MARTINEZ y C. RODRÍGUEZ RUZA (eds.) Arqueología de Castilla la Mancha. I Jornadas. Cuenca 13-17 de diciembre de 2005, Cuenca, 2007, pp. 583-613; y A. ALMAGRO GORBEA, Palacios medievales hispanos, Madrid, 2008, pp. 72 y ss.

42 Véase J.C. RUIZ SOUZA, op. cit., 2001a, pp. 19-20.

43 Ibidem. 
donde se sitúa el altar mayor tenga una planta cuadrada, nos referimos a un volumen concebido de forma independiente, quedando muy clara su separación respecto a la nave mediante un arco. Acceso que en ocasiones es tan pequeño-incidiendo en la unicidad espacial del presbiterio-, que con el tiempo será agrandado para facilitar una mayor comunicación entre cabecera y nave ${ }^{44}$. Se trata del paso previo a la tabernaculización que experimentan muchos de nuestros edificios castellanos de los siglos XV y XVI. Templos en los que se que fusionan el presbiterio con el transepto, lo que constituye una macrocabecera diferenciada en sí misma respecto al resto del edificio y cuyo origen podría situarse en las experimentaciones de los siglos XIII-XIV. Ello explicaría una de las características más propias de la arquitectura religiosa castellana bajomedieval. Pero no todo es simplemente una evolución arquitectónica, ya que los cambios litúrgicos que se fueron produciendo a lo largo de la Baja Edad Media, piénsese por ejemplo en la festividad del Corpus Christi y en todo lo que conlleva la exaltación eucarística y la exposición/visualización del Santísimo, tuvo que generar unas soluciones espaciales importantes que explicarían en parte también el proceso que ahora estudiamos. Tras la bula Transitorius de Urbano IV, de 1264, junto a una serie de disposiciones del primer cuarto del siglo XIV, asistimos a la expansión de dicha festividad y al paso de una liturgia que era principalmente escuchada frente a otra que necesitaba, ahora, ser visualizada $^{45}$. Proceso que culminaba un nuevo estado de ánimo religioso al que se vinculan un sinfín de milagros como el de los Corporales de Bolsena en Italia, o el de los Corporales de Daroca en el ámbito hispano, entre otros, producidos en el siglo XIII. No parece casual que dicho proceso arquitectónico-espacial y litúrgico coincidan cronológicamente en su desarrollo. Al final la cabecera de la iglesia se convierte en un gran tabernáculo, en una especie de gran custodia. Todo ello además viene unido a la lucha que se desencadena por acotar y privatizar las cabeceras templarias para convertirlas en lugar de enterramiento privilegiado ${ }^{46}$. Todas ellas, son causas esenciales en la evolución del espacio presbiterial. Al fin y al cabo es lógico que ambos procesos se solapen y converjan.

Vayamos a los ejemplos concretos. En algunos edificios que hemos estudiado en otros trabajos como la Capilla de la Asunción en las Huelgas de Burgos o la del Santísimo Sacramento en Santa Marina de Sevilla, ambas del último tercio del siglo XIII, o la de San Pablo de Córdoba ya del siglo siguiente, al presentar un vestíbulo

44 Proceso que se produjo por ejemplo en el caso de las dos qubbas funerarias del monasterio de Tentudía, que flanquean su presbiterio.

45 Véanse al respecto los trabajos, y muy especialmente sus introducciones de C.A. BRUZELIUS, "Hearing is believing: Clarissan Architecture, ca. 1213-1340", Gesta, XXX/2 (1992), pp. 83-91; y M.V. HERRÁEZ ORTEGA, "Orfebrería y liturgia en la Baja Edad Media. El programa iconográfico de la custodia procesional de Córdoba”, Anales de Historia del Arte, 4 (Homenaje al prof. Dr. D. José María de Azcárate) (1994), pp. 383-392.

46 I.G. BANGO TORVISO, "El espacio para enterramientos privilegiados en la arquitectura medieval española", Anuario del Departamento de Historia y Teoría del Arte, IV (1992), pp. 93-132, especialmente pp. 128 y ss. 
muy poco profundo, o antecuerpo de entrada, parecen anunciar el paso siguiente, es decir, el de dotar a éste de mayor dimensión, configurando dos espacios: la entrada convertida en nave, y la qubba, propiamente dicha, en presbiterio. En el propio cenobio burgalés, las capillas del Salvador y de Santiago, del último tercio del siglo XIII, parecen culminar dicho proceso, al contar con una nave independizada de la cabecera cuadrada $^{47}$. Similar tipología se estudia en el caso de la Capilla Real de Córdoba fundada en 1371 por Enrique II. Se trata de una qubba funeraria que privatiza el extremo oriental de la nave mayor de la primera catedral medieval inserta en la mezquita cordobesa, de la cual se independiza claramente, y solo se une a ella mediante dos puertas laterales en alto. Dicha fundación funeraria fue materializada por el mencionado monarca con las formas nazaríes del último tercio del siglo XIV. Capilla que seguramente imitaba la solución tipológica que presentaba a finales del siglo XIII la Capilla Real de Sancho IV en el presbiterio de la Catedral de Toledo ${ }^{48}$.

Debemos recordar el carácter tan dinámico que tuvo Andalucía en el desarrollo del nuevo modelo arquitectónico que ahora nos ocupa, entre los últimos años del siglo XIV y todo el siglo XV. Este proceso por el cual el presbiterio de la iglesia, que no suele tener carácter funerario, aparece ocupado por una qubba es bien conocido en el Aljarafe sevillano ${ }^{49}$ y en Extremadura en donde igualmente se observa a lo largo de la Baja Edad Media la construcción de templos con su cabecera independizada por una qubba, tal como se contempla en la iglesia funeraria de los Suárez de Figueroa, duques de Feria, en el Convento de Santa Clara de Zafra.

La técnica tradicional de espacio cuadrado cubierto con cúpula de paños sobre trompas de semibóvedas de arista, es decir la técnica que presentan la mayoría de las qubbas del norte de África ${ }^{\mathbf{5 0}}$, así como las hispanas (musulmanas primero y cristianas después), termina por agotarse e inicia su desaparición a lo largo de la primera mitad del siglo XV, ante las posibilidades que traía consigo la arquitectura europea de nervios y ojivas. Ello es muy palpable en la interesante Iglesia de Nuestra Señora de la Oliva de Lebrija. La etapa medieval de la iglesia se componía de

47 G. PALOMO FERNÁNDEZ y J.C RUIZ SOUZA, "Nuevas hipótesis sobre las Huelgas de Burgos. Escenografía funeraria de Alfonso X para un proyecto inacabado de Alfonso VIII y Leonor Plantagenêt", Goya, 316-317 (2007), pp. 21-44.

48 Sobre la problemática de las capillas reales, y muy especialmente de las de Córdoba y Toledo, con la reinterpretación de sus cabeceras véase J.C. RUIZ SOUZA, "Capillas Reales funerarias catedralicias de Castilla y León: Nuevas hipótesis interpretativas de las catedrales de Sevilla, Córdoba y Toledo”, Anuario del Departamento de Historia y Teoría del Arte, XVIII (2006), pp. 9-29.

49 D. ANGULO, Arquitectura mudéjar sevillana de los siglos XIII, XIV y XV, Sevilla, 1932; L. TORRES BALBÁS, "Dos obras de arquitectura almohade: la mezquita de Cuatrohabitan y el castillo de Alcalá de Guadaira", Al-Andalus, VI (1941), pp. 204-216; y A. MORALES MARTÍNEZ, "Reflexiones sobre algunas iglesias mudéjares del Aljarafe sevillano", Mudéjar iberoamericano una expresión cultural de dos mundos, Granada, 1993, pp. 39-54. A. Morales Martínez estudia de forma monográfica los ejemplos de Castilleja de Talhara, Gelo, Benacazón y Aznalcóllar.

50 S. CAUVET (commandant), "Les marabouts. Petits monuments funéraires et votifs du Nord de 1'Afrique", Revue Africaine, 64 (1923), pp. 274-329 y 448-522. 
doce qubbas, y en una de las conservadas en la nave del Evangelio, curiosamente, vemos que se ha pintado sobre la trompa de semibóvedas de arista tres nervios para intentar simular que se trata de una obra de técnica gótica.

La unión de la idea de contar con una qubba en el presbiterio y la nueva técnica del último gótico procedente de Europa, hará posible, como ya se ha dicho más arriba, la creación de una tipología de iglesia muy repetida en la segunda mitad del siglo XV y durante buena parte del siguiente en la Corona castellana. Son muchos los ejemplos, cada uno con su problemática particular, que podríamos citar repartidos a lo largo y ancho de la Corona, construidos entre los siglos $\mathrm{XV}$ y $\mathrm{XVI}^{51}$ : Nuestra Señora del Parral en Segovia, Capilla de Mosén Rubí en Ávila, San Francisco de Medina de Rioseco, San Juan de los Reyes (fig. 7), la interesante iglesia del monasterio toledano de Montesión en donde hacia 1500 su cabecera centralizada ${ }^{\mathbf{5 2}}$

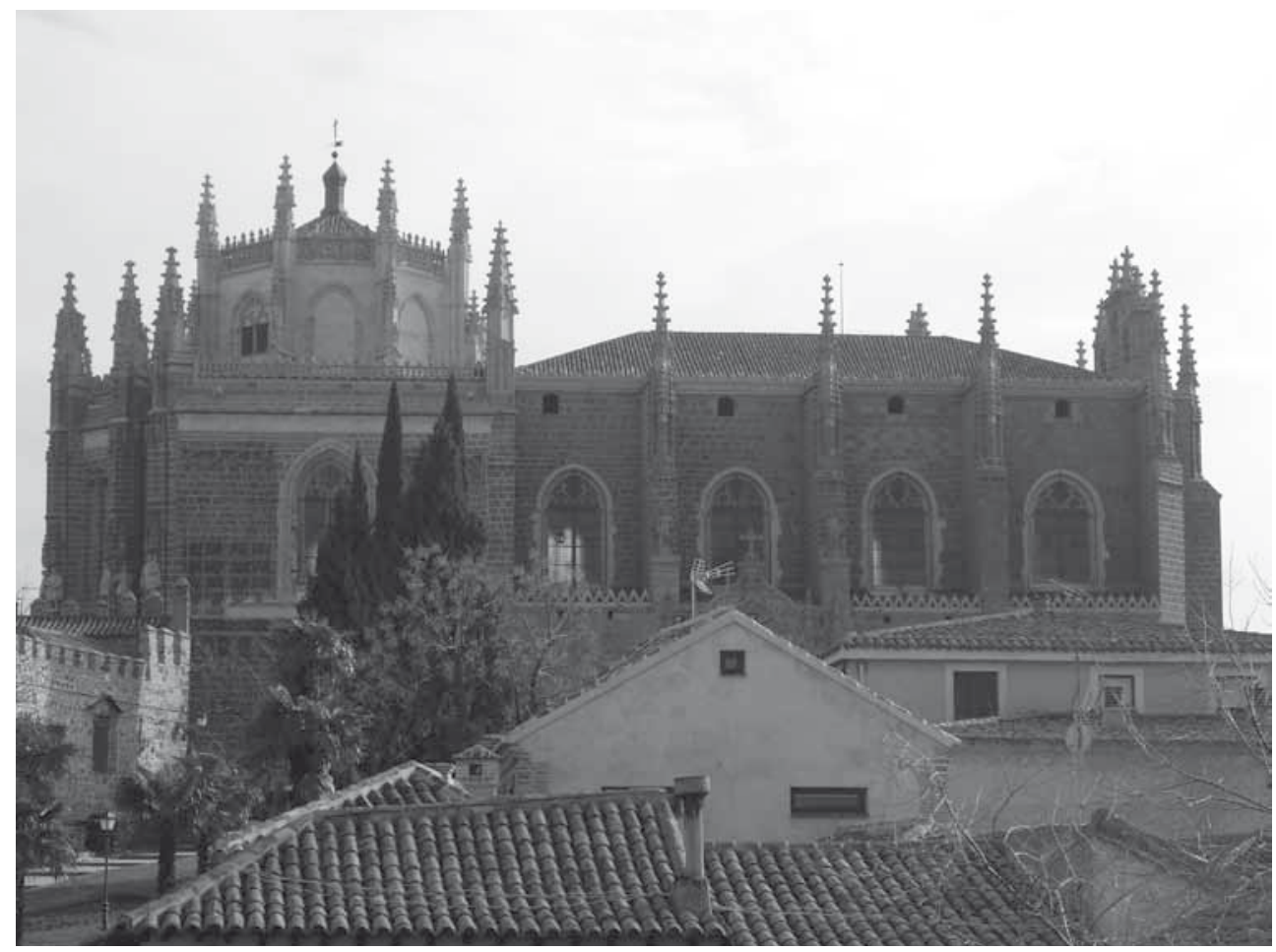

Fig. 7. Iglesia de San Juan de los Reyes, finales del siglo XV (Toledo).

51 Este proceso de creación de grandes cabeceras con un sentido funerario ha sido estudiado por I.G. BANGO TORVISO, op. cit., 1992, pp.128 y ss.

52 Arquitecturas de Toledo. I. Del Romano al Gótico, Toledo, 1992, pp. 545-555. 
se independiza de la nave, o años más tarde, ya en pleno siglo XVI, asistimos a la construcción de la impresionante cabecera de la Iglesia parroquial de Santoyo (Palencia), a la del templo del monasterio premonstratense de la Vid, o a la interesante iglesia del monasterio de Santa Clara de Briviesca entre mucho otros edificios ${ }^{\mathbf{5 3}}$.

La cabecera de muchos de estos templos son sencillamente presbiterios privatizados con carácter funerario. La identificación de dicha planta centralizada con lugares de entierros privilegiados es tan sobresaliente que hará que antiguas cabecera de tres ábsides se derriben ante el deseo de construir una gran qubba funeraria. Así, por ejemplo, la iglesia-panteón del Monasterio benedictino de San Salvador de Oña (Burgos), sede de uno de los panteones más importantes de la Castilla Condal, ve cómo se derriba su antigua cabecera de tres ábsides románicos para erigir en pleno siglo XV otra de planta cuadrada cubierta por una preciosa bóveda estrellada. Presbiterio al que se trasladan desde otra capilla del templo el importante conjunto de sepulturas altomedievales que ahora se monumentalizan con elegantes cenotafios tardogóticos de madera decorados con sargas pintadas ${ }^{\mathbf{5 4}}$. Igualmente podríamos decir de la Colegiata de San Bartolomé de Belmonte (Cuenca), cuya cabecera, claramente descoordinada respecto a las tres naves del templo, pertenece a un proyecto posterior al mismo. Dicho presbiterio fue iniciado en la segunda mitad del siglo XV y posiblemente finalizado a principios del siguiente. En él se ha visto la escuela toledana de Hanequín de Bruselas y Egas Cueman. Interesante cabecera ultrasemicircular que se convertiría en uno de los panteones principales de los marqueses de Villena ${ }^{\mathbf{5 5}}$.

La tipología de qubba continuó a pesar de los cambios experimentados en los lenguajes artísticos. Es necesario observar la insistencia de la tradición del espacio ochavado durante el siglo XVI, tal como se demuestra en el conocido deseo que $\mathrm{D}^{\mathrm{a}}$ Aldonza de Vivero, condesa de Osorno, muestra en 1512 para convertir en "ochavada la capilla donde está enterrado su marido en la iglesia de Trinitarios Calzados de Burgos" ${ }^{\text {\$6 }}$. Ni que decir tiene que ella no estaría pensando para nada en la qubba andalusí, ni en su origen martirial antiguo, ni en sus consecuencias... La planta centralizada y su relación con lo funerario y la eternidad es algo inherente al ser humano. Pero lo que queda muy claro es la fuerte tradición que existió durante la Baja Edad Media en la Corona castellano-

53 Véase al respecto el trabajo fundamental de B. ALONSO RUIZ, Arquitectura tardogótica en Castilla. Los Rasines, Santander, 2003, especialmente pp. 139 y ss., y el artículo de la misma autora "Un modelo funerario del tardogótico castellano: las capillas treboladas", Archivo español de arte, 311 (2005), pp. 277-295.

54 Véase la transformación y planimetría de la cabecera del monasterio de Oña en J.L. SENRA GABRIEL Y GALÁN, "El monasterio de San Salvador de Oña (Burgos): del románico pleno al tardorrománico", Alfonso VIII y su época, II Curso de Cultura Medieval, Madrid, 1992, pp. 339-353.

55 A. DE LA MORENA, La España Gótica. Castilla-La Mancha I, Madrid, 1997, p. 129. J.C. RUIZ SOUZA. "Al-Andalus reinterpretado y asimilado. Particularísmos arquitectomicos en las Corona de Castilla en los siglos XV y XVI" en B. ALONSO RUIZ (ed.). La arquitectura gótica castellana entre Europa y América, Madrid 2011, pp. 313-324, esp. p. 321.

56 J. RIUS SERRA "Subsidios para la historia de nuestra cultura. II siglos XIV-XVI", Archivo Español de Arte y Arqueología, 15, 5 (1929), pp. 247-274, doc. CXV, p. 272. Cfrs. L. TORRES BALBÁS, "Arquitectura Gótica”, Ars Hispaniae, vol. VII, Madrid, 1952, p. 296. 
leonesa respecto a otros lugares de la propia Europa. Las lecturas iconológicas que queramos realizar, por muy viables y plausibles que éstas sean, deben ser a posteriori y complementarias, respecto a una tradición constructiva ya existente.

El gran valor de la Colegiata de Belmonte es la evidencia de la existencia de una línea de investigación arquitectónica que se estaba debatiendo en las últimas décadas del siglo $\mathrm{XV}$, cuyo punto final se puede encontrar en Granada. Al estudiarse un edificio tan emblemático como la Catedral de Granada, además de recordarse la cabecera de la catedral de Toledo de tres siglos antes, debería hacerse igual hincapié en la tradición que ahora exponemos, y no debería pasar desapercibida entre sus precedentes, al menos en lo que a la tipología de su presbiterio se refiere, la citada Colegiata de Belmonte, la cual sólo se adelanta cronológicamente en unas pocas décadas. No es un edificio más, ya que se vincula a los poderosos marqueses de Villena que llegaron a detentar el maestrazgo de la Orden de Santiago, tal como fue el caso de Juan Pacheco, quien consiguió en 1459 que la iglesia belmonteña alcanzase el grado de colegiata.

\section{Del arco del triunfo a la fachada parlante}

En la arquitectura civil hallamos igualmente muy interesantes aspectos y posiblemente el desarrollo que adquiere la fachada en las construcciones palatinas sea el más sobresaliente de todos ellos ${ }^{57}$. Es sobradamente conocida la importancia que adquiere la escritura monumental exterior en las arquitecturas romanas e islámicas. En Al-Andalus, desde época omeya, era común introducir inscripciones amplias explicativas en las fachadas y entradas de los edificios, religiosos y civiles, al igual que en todo el mundo antiguo y tardoantiguo de la romanidad.

Todavía se conserva la inscripción que aparece en el dintel de la puerta de San Esteban de la Mezquita de Córdoba que nos explica la intervención del emir Muhammad I en el 855-856, así como otras ubicadas en lugares destacados de otros edificios andalusíes que nos hablan del señor y artífice de una determinada obra, como todavía hoy se contempla en la que preside la fachada del Cristo de la Luz en Toledo fechada en el año 999. Inscripciones que evidentemente también se encuentran en el ámbito cristiano, algunas con un protagonismo destacado, tal como se comprueba en el pórtico de la Gloria de la catedral compostelana, si bien, el desarrollo que alcanza en Al-Andalus es infinitamente mayor, ante las connotaciones que adquiere la escritura en el ámbito islámico, frente a otros medios de comunicación visual. El edificio llega a hablar a través de sus inscripciones en primera persona, tal como se comprueba en la propia Alhambra ${ }^{\mathbf{5 8}}$.

57 Temas que hemos desarrollado en J.C. RUIZ SOUZA, op. cit., 2004a.

58 Respecto a las inscripciones de la Alhambra véase el reciente y magnífico trabajo de J.M. PUERTA VÍlCHEZ, Leer la Alhambra. Guía visual del monumento a través de sus inscripciones, Granada, 2010. Entre otras pueden recordarse las célebres inscripciones de la fachada de Comares (pp. 69-73) o del mirador de Lindaraja en el Palacio de los Leones (pp. 226 y ss.). 
Escritura monumental que volvemos a ver con profusión en los palacios castellanos del siglo XV. En casi todos los casos prima la autopropaganda del promotor que quiere dejar impronta de su fama en la puerta de la construcción por él auspiciada, como si de un antiguo arco del triunfo se tratase. Un siglo antes, en el mundo nazarí se llegó a un gran desarrollo en las fachadas de todo tipo de construcciones. La madrasa de Yusuf I, el maristán de Muhammad V, la fachada de Comares erigida por el mismo sultán, o las grandes puertas de la muralla de la Alhambra, presentan monumentales portadas con importantes y extensos textos explicativos, todos ellos del siglo XIV. Portadas que adquieren un protagonismo tan desmesurado que son en sí mismas elementos independientes del edificio. Lo mismo podría decirse de las fachadas de los palacios de Pedro I en Tordesillas y Sevilla. Si en Tordesillas se cantan las victorias míticas de su padre Alfonso XI, en el sevillano directamente se alude al propio rey don Pedro, como promotor no del palacio, sino de la fachada, a la que se dota de autonomía propia, lo que supone un salto cualitativo muy interesante.

A partir del siglo XIV la heráldica será fiel compañera de la escritura en las fachadas, al principio de forma tenue como en la de Comares (Alhambra) o en la de la Montería (Alcázar de Sevilla). Después, en el siglo XV, la unión de ambos elementos alcanza un gran desarrollo en las construcciones castellanas, e incluso en ocasiones la heráldica será la única que aparezca. Proceso que fuera de la Península no veremos con semejante desarrollo en ningún otro lugar de Europa.

Algunas obras castellanas como las fachadas del palacio de Cogolludo y del Infantado de Guadalajara, la de la Casa del Cordón en Burgos, la del palacio de los Contreras en Ayllón, la desaparecida de la casa de los Osorio en Astorga, la del palacio de los Duques de Arcos, trasladada a los jardines del Alcázar de Sevilla desde Marchena, como tantas otras, no deben desvincularse del paisaje monumental hispano de la época. Todo parece indicar que se toman las diferentes tipologías de fachada existentes en Al-Andalus, pero materializadas con el lenguaje formal del último gótico, a veces del renacimiento italiano, o en ocasiones de ambos y con algún detalle andalusí. José María de Azcárate ${ }^{59}$ llamó la atención sobre este aspecto al estudiar las obras de Juan Guas, en cuyas construcciones observa la reinterpretación de "temas decorativos" y "organizaciones estructurales" de arquitecturas hispanas previas.

Continuamente se pone en relación el aspecto del palacio de Cogolludo (fig. 8) con esquemas italianos, si bien, es admisible que se pueden establecer claras conexiones, vemos de igual manera que no todo queda explicado desde Italia. La personalidad de artistas de la talla de Lorenzo Vázquez, perfectamente conocedor de lo hispano y de lo italiano, explican las peculiaridades del palacio. El almohadillado era un elemento conocido desde antiguo como se demuestra en la puerta romana de Sevilla en Carmona, o en las fachadas de los palacios del rey don Pedro

59 J.M. AZCÁRATE, "La fachada del Infantado y el estilo Juan Guas”, Archivo Español de Arte, 24 (1951), pp. 307-319. 


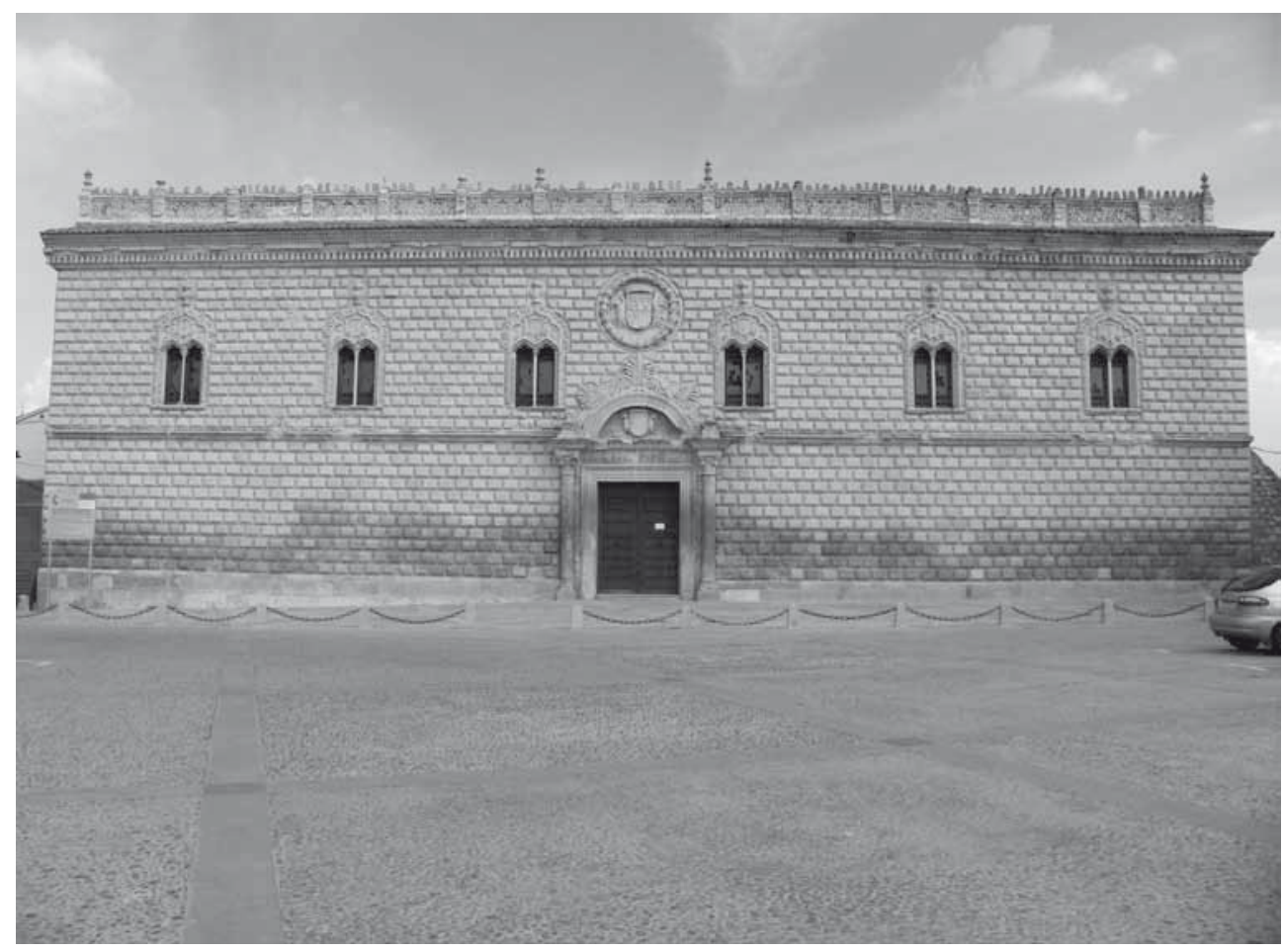

Fig. 8. Palacio de Cogolludo, ca. 1492 (Guadalajara).

en Sevilla y Tordesillas. Su desarrollo en Cogolludo no alcanza ni el relieve ni el protagonismo de los casos italianos. Por otra parte en la Corona de Castilla las fachadas de los palacios concentran casi en su totalidad la información heráldica, escrita o figurada junto a la puerta de acceso. En el ámbito castellano suelen aparecer vanos solamente en el piso principal, siendo escasas, nulas, diminutas o posteriores las ventanas que se abren en el cuerpo inferior, y así se puede estudiar en el palacio de Jabalquinto de Baeza, en el del Infantado de Guadalajara, en la Casa de los Picos de Segovia, en el palacio de los Momos de Zamora, en la Casa de las Conchas y en la de Álvarez-Abarca de Salamanca, en el palacio de los Montarco de Ciudad Rodrigo o en el de Medinaceli de Cogolludo, entre tantos otros. En ocasiones se dota de tal protagonismo a la zona de la entrada que se llegan a desarrollar verdaderos tapices esculpidos que sobresalen por su altura y remate horizontal frente al resto del paramento, que incluso en ocasiones puede llegar a aparecer completamente desnudo y ligeramente retranqueado, como se observa en la celebérrima portada del Colegio de San Gregorio de Valladolid y posteriormente en la de la Universidad de Salamanca, ejemplos a los que ya hemos dedicado varias páginas en otros trabajos $^{60}$.

${ }^{60}$ J.C. RUIZ SOUZA, op. cit., 2004a, pp. 27-31. 


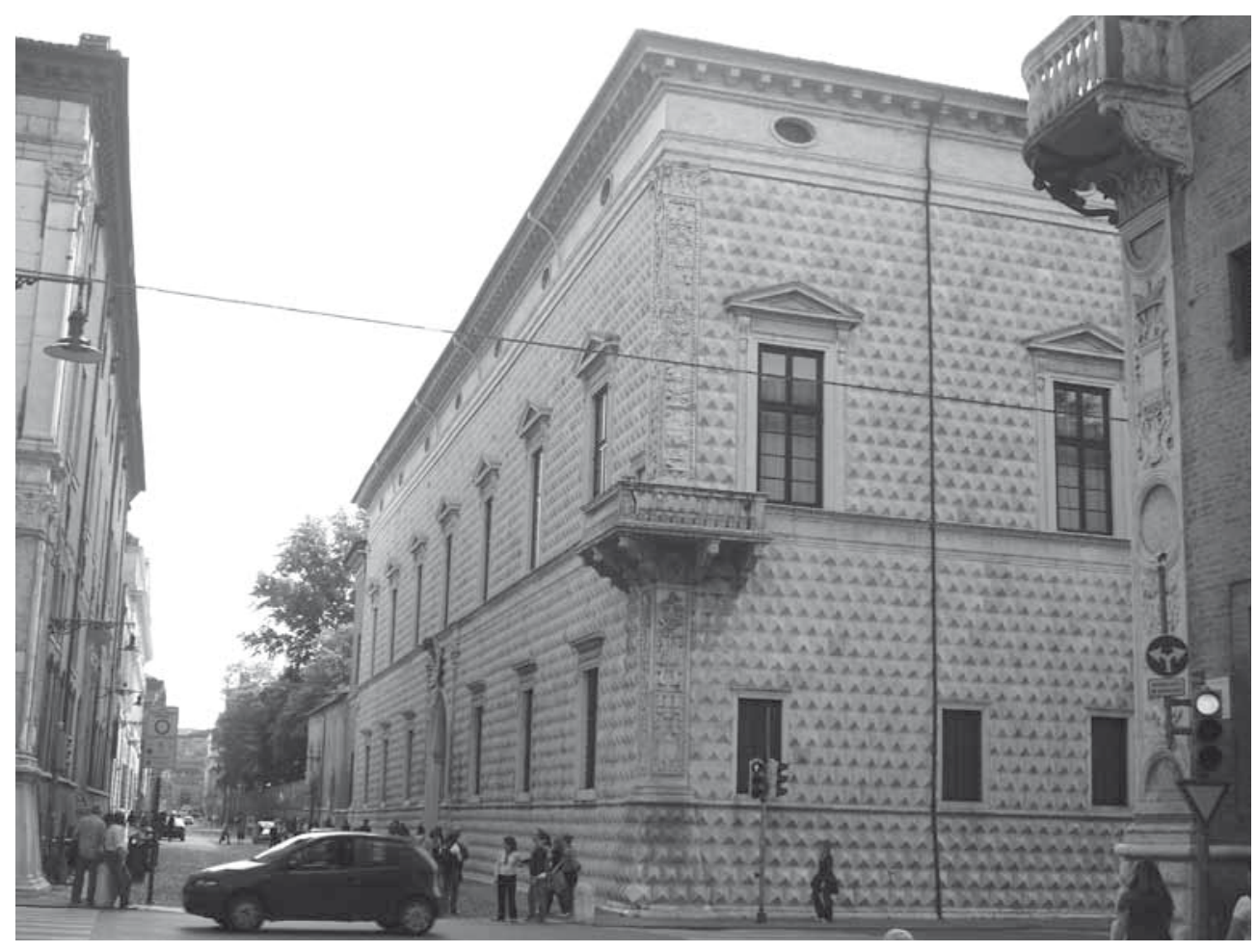

Fig. 9. Palacio de los Diamantes, siglo XV (Ferrara).

Si giramos nuestra mirada a Italia, a su rica arquitectura palatina conservada y a los ejemplos del palacio de los Diamantes de Ferrara (fig. 9) y al de Bevilacqua de Bolonia, entre muchos otros ${ }^{61}$, veremos diferencias muy considerables respecto a los palacios castellanos del siglo XV y primeros años del XVI. En Italia es una constante la apertura de grandes ventanas en todos sus cuerpos, también en el inferior, y las portadas jamás alcanzan el protagonismo que se puede observar en los palacios citados de Cogolludo, Guadalajara, Salamanca, Ayllón o Burgos. Ni siquiera en los ejemplos italianos, salvo alguna rara excepción ${ }^{62}$, la heráldica tiene un gran desarrollo y cuando ésta aparece no se concentra necesariamente junto a la puerta de entrada, pudiendo aparecer en cualquier parte de la fachada y por lo general con un protagonismo muy secundario en las partes altas del edificio.

En Francia hallamos fachadas igualmente diferentes a las castellanas, tal como podemos estudiar en las actas de los congresos dirigidos por A. Renoux ${ }^{63}$, si bien

61 Véase sobre la arquitectura palatina italiana la antigua y clásica publicación de K.A. HAUPT, L’architecture des palais italiens du XIIIe au XVIIe siècle, 3 vols., París, 1930.

${ }^{62}$ Caso de la fachada de La Carta del siglo XV erigida entre la basílica de San Marcos y el Palacio Ducal.

63 A. RENOUX (dir.), Palais Royaux et princiers au moyen age, Actes du colloque international du Mans, Octobre 1994, Le Mans, 1996; A. RENOUX (dir.), Aux marches du palais: qu'est-ce-qu'un palais 
se observa un mayor protagonismo de la portada (ejemplos del castillo de FertéMilón, del palacio ducal de Nancy o del palacio de Jacques-Coeur de Bourges), y aunque no es extraña la utilización de la heráldica nunca llega al desarrollo que puede observarse en Castilla.

En el mundo islámico medieval existen unos iconogramas muy bien definidos que nos permiten saber ante qué tipo de edificio nos hallamos. Aquéllos de carácter filantrópico, como las madrasas o los maristanes, suelen presentarse con un exterior muy cerrado y desnudo, donde sólo descuella la portada por la profusión decorativa con la que es tratada y por disponerse en ella toda la información alusiva a la funcionalidad y promotor del edificio. Madrasas de Marruecos, Egipto, Siria, Turquía o Irán son fácilmente reconocibles simplemente por el diseño general rectangular de su gran portada, aunque presenten decoraciones muy distintas ${ }^{64}$. Lógicamente en Granada también existieron edificios de similar funcionalidad.

El Maristán de Granada construido por Muhammad V entre 1365 y 1367 nos es conocido gracias a los dibujos que de él se realizaron en el siglo XIX antes de su derribo. Destaca su gran fachada desnuda en cuyo eje central se disponía la puerta de entrada y la gran inscripción alusiva a su fundación, hoy conservada en el $\mathrm{Mu}$ seo de la Alhambra. Existen dos interpretaciones respecto al tratamiento del resto de la fachada. En el dibujo de mediados del siglo XIX del arquitecto granadino F. Enríquez, realizado al ser derribado el edificio y al que alude Leopoldo Torres Balbás $^{65}$ en su estudio monográfico, se disponen en el piso superior del edificio una serie de ventanas. Las investigaciones llevadas a cabo por Antonio Almagro y Antonio Orihuela ${ }^{66}$ realizan una nueva propuesta en la que se suprimen dichos vanos, por lo que la parte central de la fachada aumenta, si cabe, en protagonismo.

Respecto a las fachadas que pudieran tener las madrasas andalusíes poco podemos decir. De la fundada por Yusuf I en 1349 se han conservado varios restos de sus inscripciones en el Museo Arqueológico de Granada, pero respecto a su diseño general existen más dudas que certezas. Se sabe que contaba con dos grandes inscripciones, las cuales son colocadas sobre la puerta de entrada por Antonio Almagro Cárdenas, y a sus lados por Rafael Contreras ${ }^{67}$. Desde nuestro punto de vista nos parece más viable la solución del primero, ya que por los ejemplos conservados

medieval? Actes du VII Congrès Internacional d'archeologie Médiévale. Le Mans - Mayenne 9-11 septembre 1999, Le Mans, 2001.

${ }^{64}$ Tal como observamos en la compilación realizada en la publicación de L. GOLVIN, La madrasa médiévale, Aix-en-Provence, 1995.

${ }^{65}$ L. TORRES BALBÁS, "El Maristán de Granada”, Al-Andalus, 9 (1944), pp.481-498.

${ }^{66}$ A. ALMAGRO GORBEA y A. ORIHUELA UZAL, "El Maristán Nazarí de Granada. Análisis del edificio y una propuesta para su recuperación”, Boletín de la Real Academia de BB AA de Ntra. Sra. de las Angustias de Granada, 10 (2003), pp. 81-109.

67 A. ALMAGRO CÁRDENAS, Estudio sobre las inscripciones árabes de Granada, Granada, 1879; y R. CONTRERAS, Estudio descriptivo de los monumentos árabes de Granada, Sevilla y Córdoba, Madrid, 1878 . 
lo habitual es colocar las inscripciones en la parte superior de las fachadas. Desgraciadamente nada conocemos respecto a la fachada del Palacio de los Leones ${ }^{\mathbf{6 8}}$.

Si comparamos todas las fachadas castellanas citadas en estas páginas con las que conocemos de Granada, y con las que por ejemplo presentan multitud de madrasas en otros ámbitos islámicos, nos llamará la atención que en gran medida se pueden trazar conexiones de carácter general, en lo que respecta a la disposición y diseño de todas ellas, aunque el vocabulario formal en que estén realizadas cambie radicalmente. Si un musulmán en el siglo XVI visitase Valladolid y Salamanca no dudaría en pensar que se hallaba ante dos instituciones dedicadas a la enseñanza frente a las fachadas de San Gregorio y de la universidad salmantina.

No debemos olvidar que durante la Edad Media en el mundo islámico se había configurado desde mucho tiempo antes una tipología de edificio destinado a la docencia, lo cual no había sucedido en el occidente europeo. Si en París, Londres, Bolonia o Salamanca la universidad es ante todo una institución que desarrolla su actividad en diversos espacios y lugares vinculados con la Iglesia, en Granada, Fez, El Cairo, o Damasco, la madrasa se vincula con una institución y con un local propio perfectamente definido. Si en París sólo existe una universidad, en Fez existen a la vez numerosas madrasas $^{69}$. Por ello creemos que obras artísticas del último medievo tan singulares como las fachadas de San Gregorio de Valladolid y de la Universidad de Salamanca deban comprenderse dentro del paisaje monumental, hoy perdido, pero que en el siglo XV existió en la propia Península, en el Reino de Granada, considerado como un referente mítico en la conciencia de la monarquía, nobleza y clero de Castilla. Los geniales artistas que las concibieron pudieron encontrar en el emirato nazarí una tipología de fachada, ideal para unas construcciones de similar funcionalidad.

\section{La plaza o el vaco de España ${ }^{70}$. La incógnita de la crujía meridional del palacio de Comares de la Alhambra (s. XIV)}

Todavía creemos que está sin resolver el tema del flanco meridional del palacio de Comares de la Alhambra, donde se erigió en la primera mitad del siglo

68 Edificio que según nuestra hipótesis fue la madrasa palatina de la Alhambra. J.C. RUIZ SOUZA, “El Palacio de los Leones de la Alhambra: ¿Madrasa, Zawiya y tumba de Muhammad V?”, Al-Qantara, 22 (2001b), pp.77-120.

${ }^{69}$ Tal como nos recuerda G. MAKDISI en sus estudios, entre ellos véase por ejemplo: G. MAKDISI, "Madrasa and University in the Middle Ages", Studia Islamica, 32 (1970), pp. 255-264.

70 Agradecemos al profesor Miguel Ángel Castillo la llamada de atención que nos ha realizado sobre esta expresión del vaco o espacio de Espagna, reproducimos la información de la nota 24 de su trabajo: Expresión que aparece en Noticias históricas y genealógicas de los estados de Montijo y Teba, Madrid, 1905, pp. 321, 322, cit. por D. RODRÍGUEZ RUIZ, "El Palacio del Real Sitio de la Granja de San Ildefonso. Un retrato cambiante del rey", El Real Sitio de La Granja de San Ildefonso. Retrato y escena del rey, Madrid, 2000, p. 34; y M.A. CASTILLO OREJA, "Ideas, composición y diseño: Antecedentes programáticos y precedentes tipológicos tradicionales del Escorial”, El monasterio del Escorial y la Arquitectura, San Lorenzo de Escorial, 2002, pp. 18-19. 
XVI el Palacio de Carlos V. Espacio que nosotros consideramos fundamental en la concepción de la plaza que precede a los palacios bajomedievales castellanos. En otro estudio hemos especulado sobre la disposición de toda esta zona ${ }^{71}$, en la que pensamos se abría un amplio espacio a modo de plaza de representación, que a la postre explicaría que aquí se erigiese el palacio renacentista del Emperador ${ }^{72}$. Lugar en donde convergen las vías más importantes que articulaban la ciudad palatina granadina ${ }^{73}$. No creemos casual que entre la Puerta de la Justicia y los palacios nazaríes se erija la Puerta del Vino, como si de un arco del triunfo se tratase en un punto decisivo de la ciudad. Un arco supuestamente efímero si hacemos caso a la rica decoración pintada de varios colores que aún conserva, que más bien nos hace pensar en una gran estructura conmemorativa cubierta por una enorme tela.

El flanco sur del Palacio de Comares constituye la crujía más elevada de la arquitectura nazarí conservada, al estar compuesta por tres cuerpos superpuestos. En el más alto se ve un gran arco que a su vez daría paso a un gran salón cuya cubierta, incluso, quedaría por encima de la galería que le precede, por lo que la altura de dicha crujía meridional, según nuestra hipótesis incluso sería mayor a la que actualmente presenta toda esta parte del palacio nazarí, ya que las galerías porticadas suelen preceder a una estructura de mayor altura. Es cierto que la cota del terreno de la colina de la Alhambra asciende en altura hacia el sur, por lo que la cota del patio de Comares queda a un nivel muy inferior respecto al del exterior, donde se erige el palacio de Carlos V. Desnivel que explicaría la introducción del cuerpo intermedio de dicha crujía. Nosotros creemos que el Palacio de Comares tendría una fachada hacia el exterior. ¿Qué sentido tiene la ubicación de un gran salón regio tan alto en esta parte del Palacio de Comares, y de cuya existencia no podemos dudar tras haberse conservado su puerta de acceso ${ }^{74}$. Esta hipótesis, que no es más que una especulación en voz alta tras estudiar los palacios castellanos del siglo XIV, propone para el Palacio de Comares una plaza en su flanco sur -donde se dispondría posteriormente el Palacio de Carlos V-, presidida por una gran fachada exterior con salón áulico superior desde el cual el sultán podría hacerse visible. La puerta del Vino formaría parte de todo ese escenario o plaza, a la que casualmente llegan todas las arterias principales de la ciudad palatina. No creemos que un gran

71 J.C. RUIZ SOUZA, “Tipología, uso y función del Palacio de Comares: nuevas lecturas y aportaciones sobre la arquitectura palatina”, Cuadernos de la Alhambra, 40 (2004b), pp. 77-102 y J.C. RUIZ SOUZA, "Oh lugar en que se manifiesta el rey heroico. Castilla, Granada y la cultura visual del poder en la Génesis del Estado Moderno", XIX Congreso del CEHA, Castellón 5-8 de Septiembre de 2012 (en prensa).

72 Respecto a la construcción del palacio de Carlos V, nos interesa especialmente el trabajo de Antonio Gámiz Gordo realizado al respecto. Agradecemos a dicho profesor los comentarios que nos ha realizado al respecto de este tema. Véase: A. GÁMIZ GORDO, La Alhambra nazarí. Apuntes sobre su paisaje y arquitectura, Sevilla, 2001, especialmente pp. 167-185.

73 A. GÁMIZ GORDO, op. cit., 2001, pp. 53-57.

74 Incluso no descartamos la posibilidad de que pudiera haber una comunicación desde el exterior del palacio con el patio del mismo. La arquitectura nazarí sabe resolver perfectamente esos pasos a distintos niveles tal como se comprueba en otros edificios. 
palacio como el de Comares no dispusiera de una gran fachada coetánea al mismo, ya que la que hoy conocemos con dicho nombre, entre el palacio y el mexuar, fue construida con posterioridad, en 1369, según reza su inscripción donde se alude a la conquista de la plaza de Algeciras por parte de las tropas nazaríes ${ }^{75}$.

¿Por qué pensamos en una solución así? En otras ciudades palatinas de Al-Andalus existieron espacios monumentales presidiendo plazas, caso del gran pórtico de Madinat al-Zahra. Pero lo que más nos lleva a proponer dicho planteamiento es el estudio de palacios reales castellanos de la entidad de Tordesillas y del Alcázar de Sevilla. En ambos hallamos una plaza presidida por la fachada palatina donde se disponen textos y heráldica. En el caso de Sevilla hallamos a la entrada del Patio de la Montería, junto a la actual Sala de la Justicia, un imponente arco del triunfo de tres vanos con decoración heráldica muy deteriorada en el central (fig. 10). Sobre

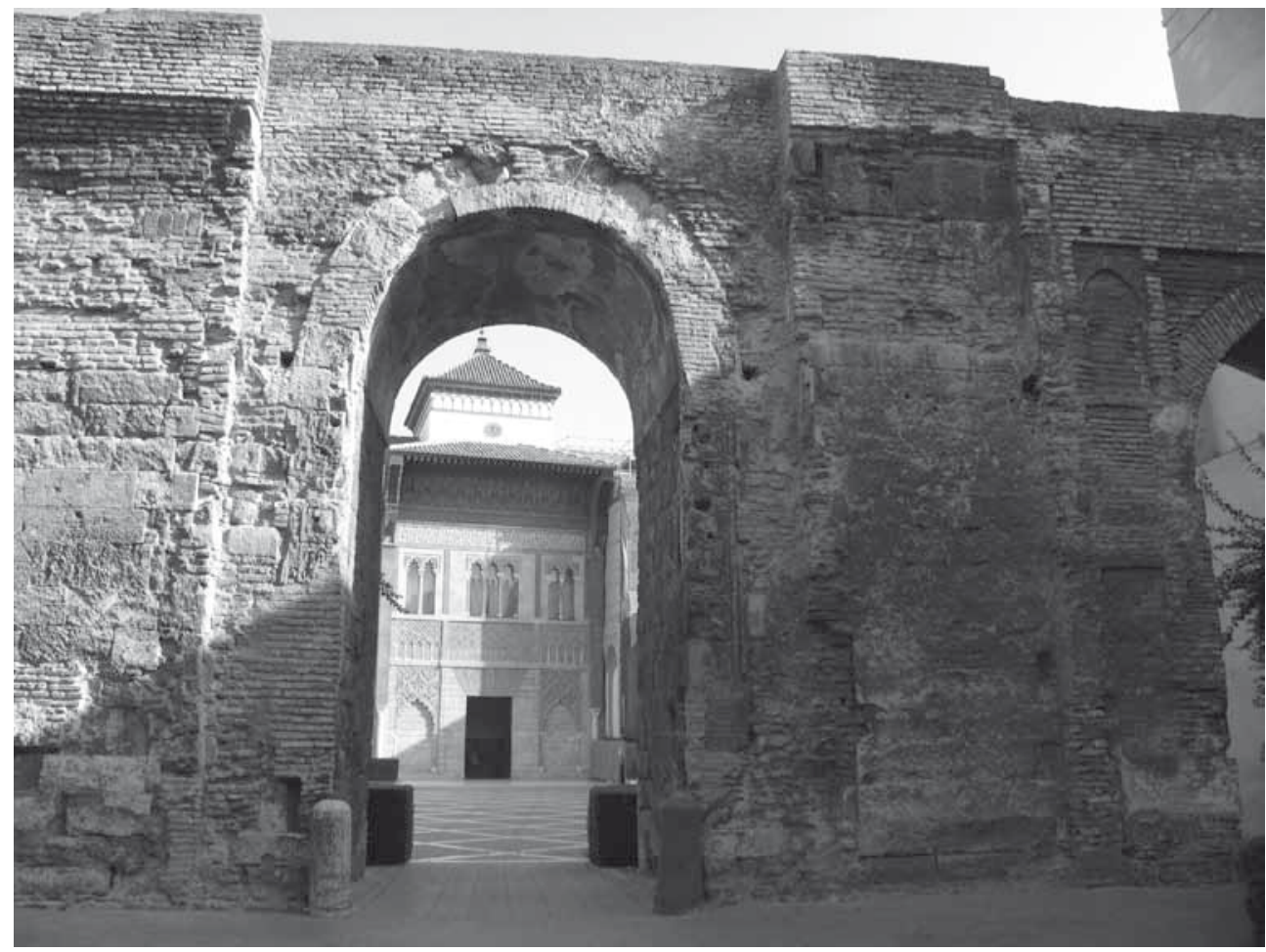

Fig. 10. Arco de acceso a la plaza del Palacio de la Montería de Sevilla, y su fachada al fondo, 1364 (Sevilla).

dicha estructura parece que pudo haber algún tipo de estructura en alto según se intuye tras la observación de los restos conservados. Tras dicha arcada triunfal se abre la plaza presidida por la majestuosa fachada del Palacio de la Montería, ya

75 J.M. PUERTA VÍLCHEZ, op. cit., 2010, pp. 69-73. 
aludida, provista de heráldica, de un gran texto laudatorio y de un salón tipo qubba en alto desde el cual el rey, Pedro I, podría hacerse visible ${ }^{76}$. Semejante despliegue propagandístico pertenece a esa "Génesis del Estado Moderno" tantas veces aludida en estas páginas. Creemos que Pedro I en Tordesillas y en Sevilla copiaba modelos andalusíes. El palacio más importante que se estaba construyendo en Granada en las décadas centrales del siglo XIV, coetáneo de los palacios de Tordesillas y Sevilla, era el Palacio de Comares, y creemos que en Castilla nos ha quedado el reflejo de lo que hubo en la Alhambra. Además, el vocabulario formal de las dos fachadas castellanas alude claramente al mundo nazarí. Además hay un elemento más que nos lleva a plantear dicha hipótesis. Entre las inscripciones que hubo en la crujía meridional del Palacio de Comares, recogido por Yusuf III a partir del diván de Ibn Zamrak, el primer verso de la gran composición poética que se ubicaba en la galería baja sobre el zócalo de alicatados decía: “¡Oh lugar en que se manifiesta el rey heroico y halo de luna siempre llena!"77. ¿Hará alusión a la funcionalidad de toda esta parte del edificio?

La idea de la plaza que precede al palacio debió ser ya práctica habitual a finales del siglo XIV en el mundo hispano, tal como se comprueba en el palacio viejo de Olite, donde Carlos III a finales de la centuria compra unas casas para derribarlas y abrir una espacio vacío a los pies del palacio ${ }^{78}$, tal como ya estaba claramente establecido en la Castilla de mediados del XIV. Seguramente la intervención de la reina Leonor, oriunda de Castilla, y con maestro de obras propio, facilitó la introducción de modelos castellanos en la política constructiva palatina de la monarquía Navarra ${ }^{79}$.

En el siglo XV, una vez más, podemos rastrear la solución aludida, pero ahora materializada con las formas del último gótico. En Ayllón Juan de Contreras erige en la villa un majestuoso palacio a finales del siglo XV (fig. 11), junto a la muralla que cierra la población. La gran fachada despliega bajo un gran alfiz, grandes escudos y una inscripción que nos habla del promotor y de los Reyes Católicos, además de dar la fecha de 1497. En un espacio angosto, entre la portada de la muralla y la fachada del palacio, se erige un pequeño arco del triunfo exornado con la heráldica de los señores de la villa, reformado en el siglo XVI, momento en el que se disponen los escudos de los marqueses de Villena que aún hoy se conservan. Dicho arco marca el verdadero arranque de la plaza que preside la monumental fachada aludida. Resulta curioso que la heráldica quede en dicho arco interno y no en la propia puerta exterior de la muralla que tiene por delante. Es muy posible que la

76 Para comprender la verdadera dimensión funcional del palacio de la Montería véase A. ALMAGRO GORBEA (dir.), La planimetría del Alcázar de Sevilla, Granada, 2000.

77 J.M. PUERTA VÍLCHEZ, op. cit., 2010, p. 85.

78 Agradecemos las continuas referencias facilitadas por Javier Martínez de Aguirre sobre el palacio real de Olite y sus etapas constructivas. Véase J. MARTÍNEZ DE AGUIRRE, Arte y monarquía en Navarra 1328-1425, Pamplona, 1987, especialmente pp. 143 y ss.

79 Ibidem, p. 144. Véase en la mencionada publicación de Martínez de Aguirre toda la documentación y la bibliografía existente al respecto, referida a las obras del Palacio Real de Olite. 


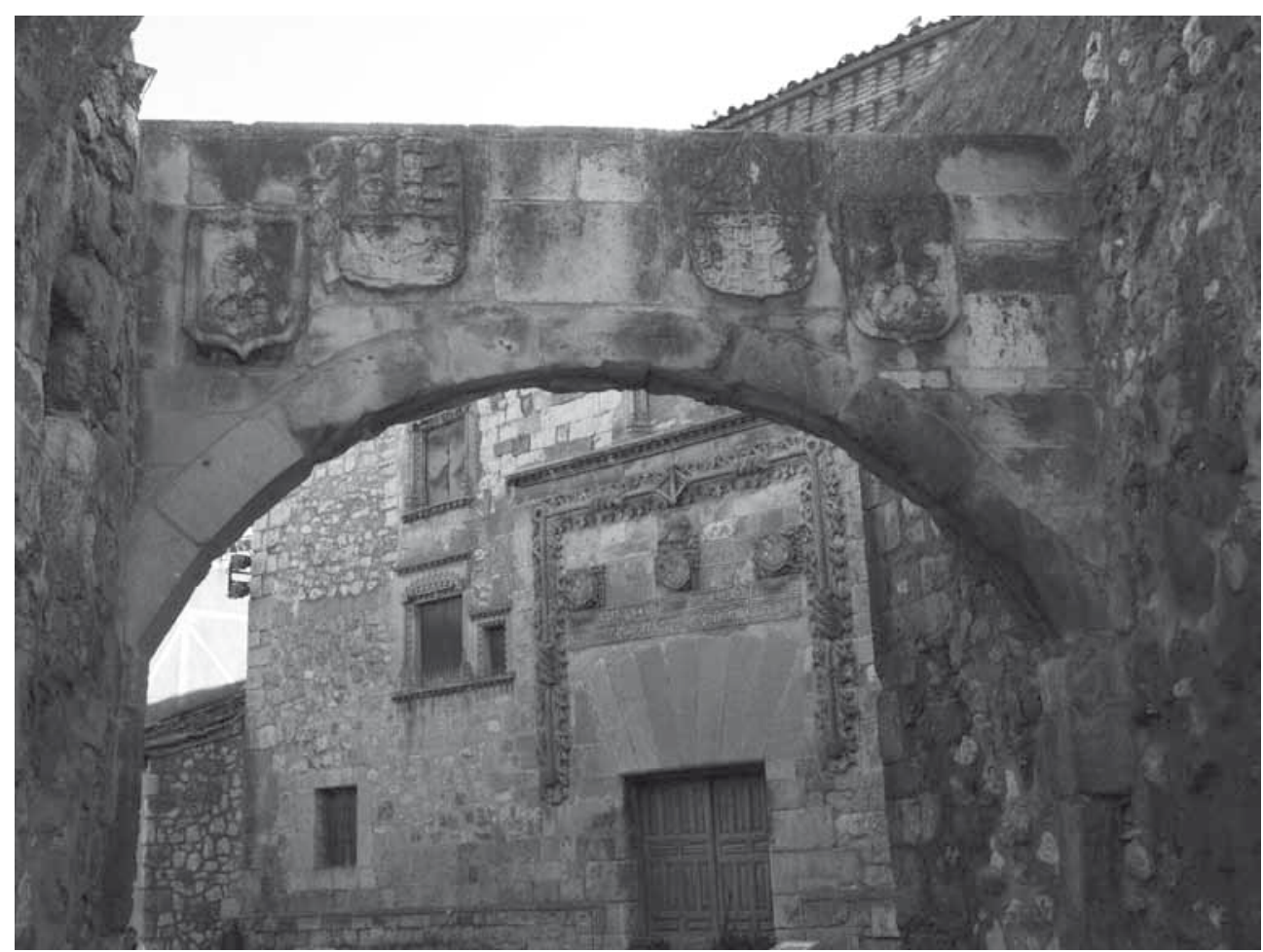

Fig. 11. Palacio de Juan de Contreras, 1497 (Ayllón).

mayor parte de los grandes palacios del siglo XV citados más arriba contasen con ese espacio previo, cuyo inicio se marcaría con una estructura triunfal.

Por si tuviéramos alguna duda sobre el carácter hispano de estos ámbitos abiertos que preceden a los palacios a modo de plaza, contamos con una interesante referencia de unos viajeros italianos que visitaban años después el país. Dicho espacio les resulta ajeno a su tradición, y no dudan en denominarlo el vaco de España ${ }^{80}$.

Nos creemos la senda marcada en los párrafos anteriores, pero los caminos no son exclusivos ni lineales, ya que se ven enriquecidos continuamente por aportes y ambientes que facilitan su discurrir. Aunque con una problemática muy diferente, podrían citarse en este discurso las torres y puertas monumentales que marcan el inicio de los compases monásticos medievales, en los que también había palacios,

80 D. RODRÍGUEZ RUIZ, "El Palacio del Real Sitio de la Granja de San Ildefonso. Un retrato cambiante del rey", El Real Sitio de La Granja de San Ildefonso. Retrato y escena del rey, Madrid, 2000, p. 34; y M.A. CASTILLO OREJA, "Ideas, composición y diseño: Antecedentes programáticos y precedentes tipológicos tradicionales de El Escorial”, El monasterio de El Escorial y la Arquitectura, San Lorenzo de El Escorial, 2002, pp. 18-19. 
caso de los cenobios cistercienses de las Huelgas de Burgos, de las Huelgas de Valladolid o del monasterio de Poblet, entre otros, o el precioso atrio monumentalizado por la reina Blanca de Navarra en la iglesia de Santa María de Olite, tan vinculada con el palacio real adyacente ${ }^{\mathbf{8 1}}$. En semejante ambiente deben entenderse monumentales estructuras posteriores de gran entidad como el Patio de los Reyes del Monasterio del Escorial ${ }^{\mathbf{8 2}}$ en donde converge la idea del vaco de España aludido y el atrio antiguo que precede a la basílica.

\section{Conclusiones: ¿Por qué Castilla? Al-Andalus ante la construcción de la cultura visual castellana. De la especulación teórica a la práctica arquitectónica}

Debe señalarse y destacarse el respeto y toma de conciencia que existió frente a la conservación de ciertos edificios emblemáticos andalusíes, como son la mezquita de Córdoba, la Giralda de Sevilla o la Alhambra de Granada, lo que explica que estas construcciones tan singulares se convirtieran en fuente de modelos de la cultura visual de la Castilla bajomedieval.

Los astures primero, los leoneses después y finalmente los castellanos, no dudaron en tomar elementos significativos, como ya hemos visto en otros trabajos, de la Mezquita de Córdoba en construcciones religiosas cristianas. La aljama cordobesa se convirtió por lo tanto en fuente de modelos de la "cultura visual de lo sagrado" desde el mismo siglo IX en adelante, si bien la conquista de la ciudad en 1236 por las tropas de Fernando III facilitó su conocimiento y valoración tal como se evidencia por los textos laudatorios que le dedican importantes y decisivos personajes de los siglos XIII y XIV de la talla de Rodrigo Jiménez de Rada, Alfonso X, Don Juan Manuel o el canciller Pero López de Ayala ${ }^{\mathbf{3 3}}$.

En la Baja Edad Media podemos estudiar como el gran alminar almohade de la mezquita aljama de Sevilla, la Giralda, y la Alhambra de Granada se convierten en otros edificios míticos a emular. Los ecos de la emblemática torre sevillana se oyen por toda Andalucía y Extremadura. Las puertas de la muralla de la Alhambra son emuladas en las fachadas de la iglesia vallisoletana de San Andrés de Aguilar de Campos de finales del siglo XV. Lo mismo podríamos decir respecto al impacto de las yeserías nazaríes o de la tipología del Salón de Embajadores del Palacio de Comares, copiada en palacios de toda la Corona castellana. Es decir, con la Alhambra parece ocurrir algo parecido a lo

81 J. MARTÍNEZ DE AGUIRRE, "El honor de la Corona: Los encargos artísticos de la reina Blanca de Navarra (1425-1441), Goya, 334 (2011), pp. 40-57, especialmente p. 52.

82 L. MOYA, "Veintiún años después”, El Escorial. Arquitectura del Monasterio, Madrid, 1986, p. 35. Visto a partir de los comentarios de M.A. CASTILLO, op. cit., 2002, pp. 19-20.

83 J.C. RUIZ SOUZA, op. cit., 2007a, pp. 210-219. 
que hemos comentado respecto a la mezquita cordobesa en otros trabajos ${ }^{84}$, al convertirse también en fuente de inspiración de la "cultura visual del poder", como ya hemos apuntado tantas veces al estudiar la arquitectura palatina y especialmente al tratar el tema de su influencia en los palacios de Pedro I en el proceso de la denominada "Génesis del Estado Moderno" 85 . Posiblemente no hayamos estudiado suficientemente el impacto que supuso el emirato nazarí de Granada en la arquitectura castellana bajomedieval, y muy en particular en la realizada durante la segunda mitad del siglo XV y primeros años de la centuria siguiente. La capital nazarí fue un mito de la Baja Edad Media, al igual que su Alhambra. No es necesario esperar a 1492 para que las obras más emblemáticas de la Granada nazarí fuesen conocidas por sus vecinos castellanos, como de hecho se demuestra, en las comentadas arquitecturas promovidas por Pedro I, en el gran desarrollo que adquiere la fachada monumental "parlante", en las decoraciones de yeserías o en los grandes salones palatinos de planta centralizada (qubbas regias) que recuerdan al gran Salón de Comares, entre otros aspectos. Conocidas son las noticias que nos hablan del empeño mostrado por los Reyes Católicos y sus inmediatos descendientes por preservar los últimos palacios de Al-Andalus ${ }^{86}$. Es conocida la sensibilidad mostrada por importantes hombres de la nobleza y de la iglesia ante lo que hallaron en Granada, siendo posiblemente los casos más reseñables el del segundo Conde de Tendilla, Íñigo López de Mendoza, capitán general del reino conquistado y primer alcaide de la Alhambra, y el de Hernando de Talavera, primer arzobispo de Granada. ¿Y los artistas? ¿Es posible imaginar que los arquitectos y maestros más importantes de Burgos o Toledo no visitasen Granada con gran interés, u otras ciudades con importantes edificios andalusíes como Córdoba y Sevilla? No tenemos duda alguna respecto a que numerosos artistas debieron llegar a Granada en compañía de los más importantes promotores. Artistas que en muchos casos pertenecerían ya a esa segunda generación de maestros procedentes del norte europeo, cuyos padres llegaron a Castilla en el reinado de Juan II, y que por lo tanto ya estarían en disposición de recoger en su arte la asimilación del paisaje monumental hispano que les rodeaba desde su infancia. Ellos también intervendrían en las obras que se sucedieron por toda la ciudad nazarí con un ritmo trepidante. Monasterios, conventos y palacios se fundan y construyen sobre antiguas edi-

${ }^{84}$ Ibidem; y J.C. RUIZ SOUZA, op. cit., 2009c, pp. 219-221 y 233-247.

85 J.C. RUIZ SOUZA, "El Palacio Especializado y la Génesis del Estado Moderno. Castilla y Al-Andalus en la Baja Edad Media”, J. PASSINI y R. IZQUIERDO BENITO (eds.), La Ciudad Medieval: de la casa principal al palacio urbano, Toledo, 2011, pp. 93-128.

${ }^{86}$ Tal como han estudiado Domínguez Casas, López Guzmán o Díez Jorge entre otros especialistas: R. DOMÍNGUEZ CASAS, op. cit., 1993, pp. 435 y ss.; R. LÓPEZ GUZMÁN, "Alhambra y mudejarismo: consideraciones sobre las intervenciones artísticas en los palacios nazaríes durante el siglo XVI", J.A. GONZÁleZ ALCANTUD y A. MALPICA CUELLO (ed.), Pensar la Alhambra, Barcelona, 2001, pp. 89-97; y E. DÍEZ JORGE, El palacio islámico de la Alhambra: Propuestas para una lectura multicultural, Granada, 1998. 
ficaciones nazaríes, muchas de ellas conservadas deliberada y conscientemente hasta la actualidad. Sería incomprensible pensar que Simón de Colonia, Gil Siloe o Juan Guas fuesen ajenos a todo lo que estaba sucediendo en la Castilla del último cuarto del siglo XV, al paisaje monumental heredado de Al-Andalus o a la propia Alhambra de Granada. A pesar de la espectacularidad de los edificios andalusíes aún hoy conservados, poco debe parecerse el paisaje monumental actual con el que se pudiera hallar durante los siglos XIV y XV, y más teniendo en cuenta el gran desarrollo que experimentaron las ciudades andaluzas durante los siglos siguientes, lo que ayudaría sin duda a la transformación de su paisaje artístico.

Después, todas estas obras que emulaban directamente las grandes construcciones de Al-Andalus, influirían a su vez en otras de los alrededores. ¿Cuánto tiempo debe transcurrir para que un elemento (técnico, formal, decorativo, simbólico) asimilado forme parte de la tradición local sin necesidad de preguntarnos dónde se encuentra su origen? ¿No distorsionamos los historiadores, desde una erudición innecesaria, la realidad al empeñarnos en buscar los orígenes remotos de cualquier elemento constructivo? ¿En cuántas ocasiones nos encontramos ante un promo-

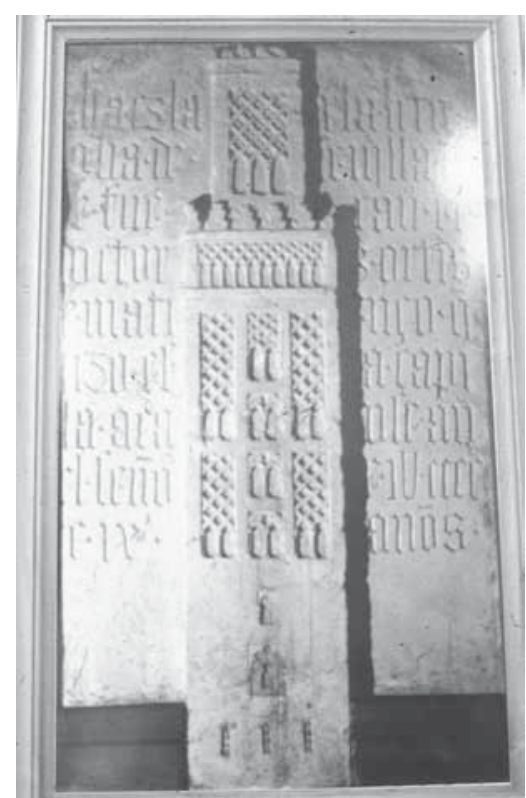

Fig. 12. Villasana de Mena, reproducción de la Giralda, 1499, en Villasana de Mena (Burgos). tor o un maestro preocupado por los diferentes orígenes de todo lo que constituía la tradición constructiva local?

Entre las conclusiones que nos gustaría transmitir al lector que lea estas páginas es que se entienda que fue necesaria la existencia de promotores que en mayor o menor grado contasen con la sensibilidad suficiente para valorar, cuidar y conservar de forma decidida algunas de las obras arquitectónicas más emblemáticas de Al-Andalus. Siempre nos gusta recordar cómo Sancho Ortiz de Matienzo, tesorero de la Casa de Contratación de Sevilla y canónigo de la catedral hispalense, mandó esculpir la Giralda sobre la lápida fundacional de su capilla en la parroquia de su pueblo natal de Villasana de Mena, al norte de la provincia de Burgos, en el año de 1499 (fig. 12), según reza la inscripción que aún rodea la imagen del famoso alminar ${ }^{87}$. Y lo mismo sucede cuando en las mismas fechas de fina-

87 L. TORRES BALBÁS, "Reproducciones de la Giralda anteriores a su reforma en el siglo XVI", $A l$ Andalus, 6 (1941), pp.216-229. 


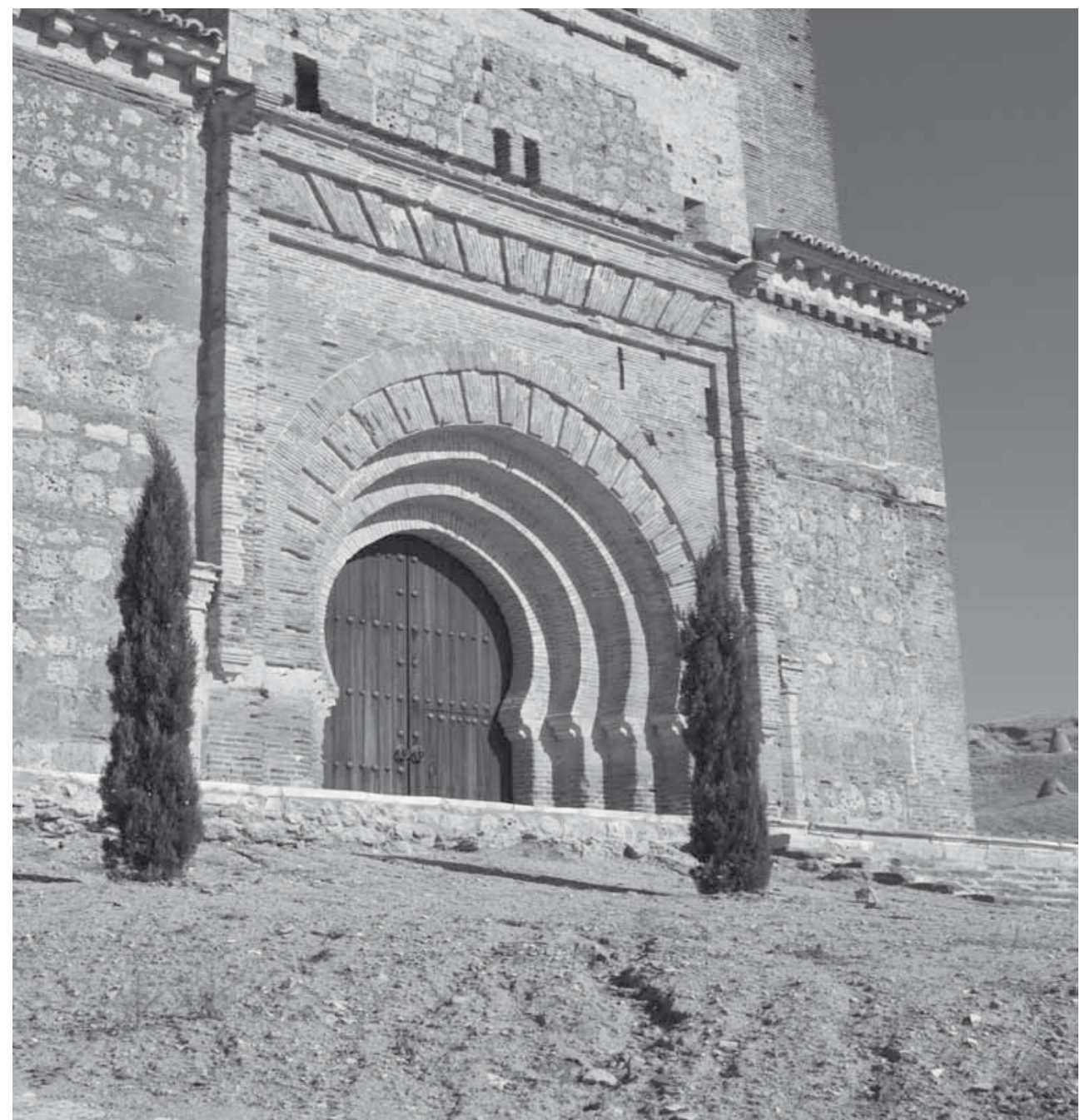

Fig. 13. Iglesia de San Andrés, finales del siglo XV (Aguilar de Campoó, Valladolid).

les del siglo XV se copian las puertas monumentales de la Alhambra en la ya aludida iglesia vallisoletana de San Andrés de Aguilar de Campos (fig. 13). Junto a ello se solapa otro proceso que viene de más atrás, como es la asunción de elementos técnicos, decorativos, tipológicos etc., de origen andalusí, pero considerados ya como propios.

Pero estos promotores y circunstancias no surgieron de forma espontánea y no pueden entenderse sin el ambiente que se había forjado en la Corona de Castilla desde tiempo antes. Hemos estudiado en otros trabajos el papel decidido de personajes de la entidad del arzobispo Jiménez de Rada y del monarca Alfonso X el 
$\mathrm{Sabio}^{\mathbf{8 8}}$. Ellos comprendieron en su invención de España la necesidad de generar un discurso integrador de lo diferente que hiciera posible la incorporación de los paisajes territoriales y culturales que se iban anexionando a la Corona en su expansión sobre los territorios de Al-Andalus. La mejor muestra de ello, tal como hemos comentado en numerosas ocasiones, la encontramos en la Estoria de España de Alfonso X. En ella vemos cómo se intercalan los capítulos en los que se habla tanto de la monarquía altomedieval astur como de la Córdoba omeya, y de los edificios de ambos como testigos que certifican la veracidad del texto relatado. Se incorpora al "otro" con una inteligente dimensión política. Seguramente todo ello tuvo su punto de arranque en el ambiente que se respiraba en el Toledo del siglo XII tras su conquista por Alfonso VI, en donde se dio la circunstancia feliz de la convergencia intelectual de cristianos, judíos y musulmanes en lo que hoy comúnmente conocemos con el anacronismo de la Escuela de Traductores de Toledo, de una forma ambigua.

La labor de Jiménez de Rada y de Alfonso X constituyó el marco especulativo teórico que hizo posible que después, durante los siglos siguientes, los promotores vieran con normalidad la conservación y asunción del paisaje cultural andalusí, y la construcción de una cultura visual específicamente castellana y poliédrica creada desde la diversidad cultural de sus territorios. Sólo así podremos comprender la responsable y consciente conservación de la Mezquita de Córdoba o de la Alhambra hasta el siglo XVII, o la labor de reyes y nobles erigiendo construcciones en donde se perciben los ecos de Al-Andalus en espacios, formas y mensajes. En muchas ocasiones se haría todo de una forma inconsciente, algo que el historiador se empeña en no entender, pues como siempre repetimos, ¿cuánto tiempo debe pasar para considerar propio a la tradición una forma, un espacio y un mensaje?

En todo este discurso vemos igualmente las diferencias evidentes entre las Coronas de Castilla y de Aragón. Castilla mostró mayor facilidad en la integración propia de las herencias de Al-Andalus que la Corona de Aragón, en donde su rico patrimonio andalusí (Aljafería de Zaragoza, palacios, mezquitas y alcázares que existieron en sus territorios) unido a la existencia de la población mudéjar más importante de la península, tal como ya apuntó el profesor Yarza ${ }^{89}$, tuvo realmente muy pocos reflejos en la arquitectura, en lugares como el Reino de Valencia, por poner sólo un ejemplo. Creemos que la inexistencia de ese marco teórico aludido es donde radica la explicación de las mencionadas diferencias.

Debe ser posible iniciar nuevos caminos llenos de posibilidades respecto al estudio de las influencias mutuas entre la arquitectura andalusí y la de sus vecinos del norte, en especial durante la Baja Edad Media, sin necesidad de reducirlo

88 J.C. RUIZ SOUZA, op. cit., 2009c; y "Alfonso X. El paisaje monumental de la Corona de Castilla: renovación e islamización”, Alfonso X, Murcia, 2009d, pp. 300-309.

89 J. YARZA, Historia del Arte Hispánico. II. La Edad Media, Madrid, 1980, p. 256. 
todo a un estilo o a una palabra, ante la riqueza de matices y sutilezas que se abren ante nuestros ojos. Siempre nos gusta repetir las mismas preguntas: ¿Cómo deberíamos estudiar obras tan sobresalientes como la Capilla del Condestable de la Catedral de Burgos, por citar tan sólo un ejemplo?, ¿No plasma la idea de la qubba islámico-andalusí, pero realizada con la técnica procedente del norte del continente?, ¿No estaría aquí la explicación de su carácter único frente al resto del gótico europeo...? Ningún historiador duda en incluirla en el arte gótico a pesar de tratarse de un espacio de filiación andalusí. ¿Qué es antes en la arquitectura: técnica o espacio para una función? Para nosotros la respuesta evidente es la segunda.

Terminaremos retomando el principio. Obras emblemáticas como la Virgen de Berruguete del Museo Municipal de Madrid o el Oratorio de Isabel la Católica en el Alcázar de Sevilla, donde se enlazan y asumen formas de muy diversas procedencias, son fruto de un larguísimo camino. Camino cuyo marco teórico de arranque se estudia en Jiménez de Rada y en Alfonso X. El epitafio de Fernando III de la catedral de Sevilla del tercer cuarto del siglo XIII (fig. 14), realizado en castellano,

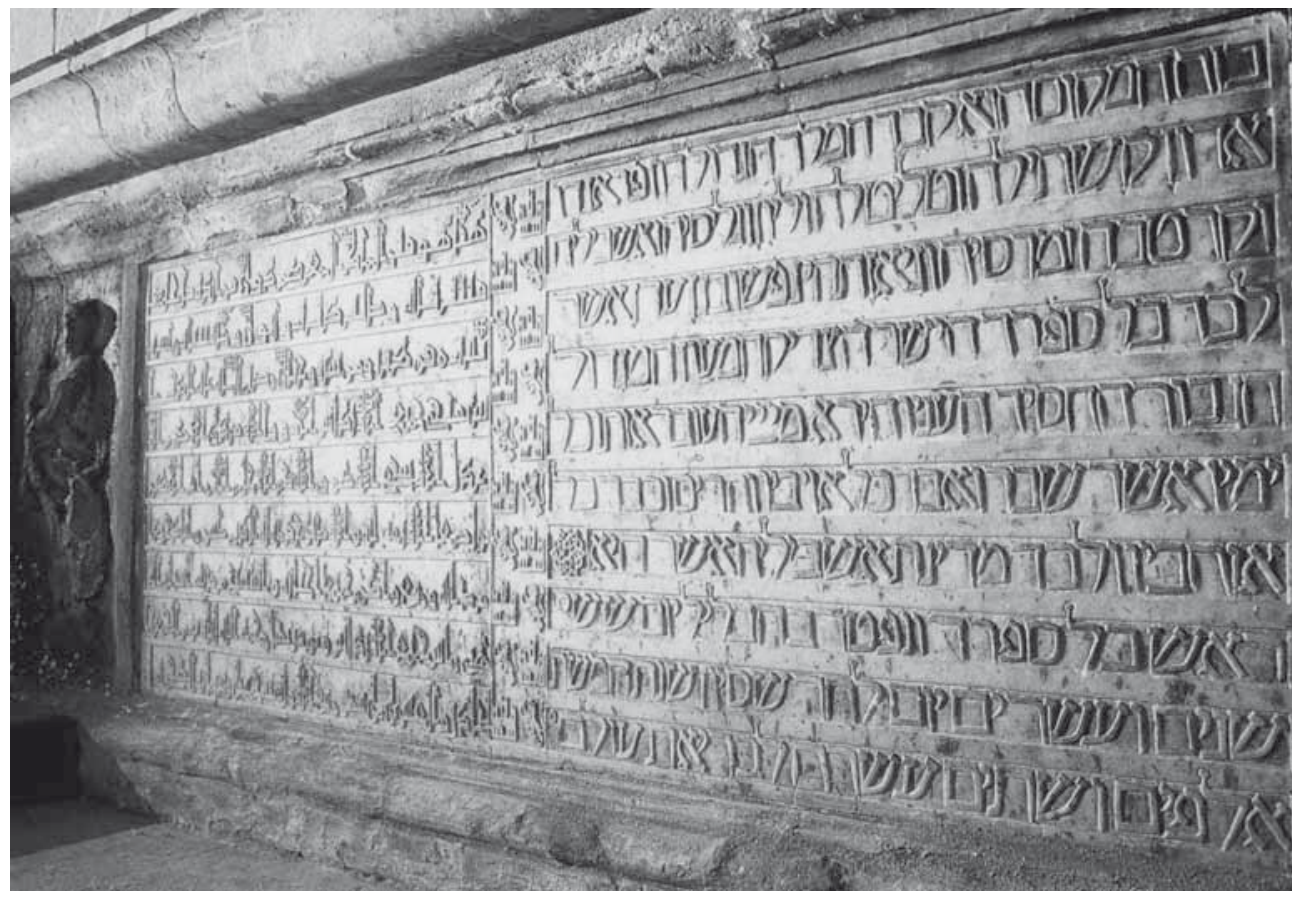

Fig. 14. Catedral de Sevilla, epitafio de Fernando III, tercer cuarto del siglo XIII (Sevilla).

latín, árabe y hebreo, es toda una declaración de intenciones que culmina y completa la práctica que ya existía en Toledo en el siglo XII, donde se encuentran ladri- 
llos sepulcrales y lápidas con epitafios bilingües ${ }^{\mathbf{9 0}}$. El epitafio hispalense supone la asunción por parte de la monarquía de la diversidad cultural de sus reinos ${ }^{\mathbf{9 1}}$. Dicho planteamiento teórico explica a la postre la singularidad del arte de la Corona de Castilla al final de la Edad Media y en el arranque de la Moderna. Sin lo que supone, teórica e intelectualmente dicho epitafio, difícilmente se hubiera realizado ni el cuadro de Berruguete ni el Oratorio de Isabel la Católica del Alcázar de Sevilla aludidos en el inicio de estas páginas.

90 En el Museo de Santa Cruz de Toledo se conserva un ladrillo bilingüe fechado en 1160 (n. de inv. 4153) y una lápida de piedra bilingüe fechada en 1189 (n. de inv. 1189), en latín y árabe en ambos casos.

91 Véase para este punto F. MÁRQUEZ VILLANUEVA, El concepto cultural alfonsí, Barcelona, 2004. 